Article

\title{
Investigation of Thermal Stability of Microstructure and Mechanical Properties of Bimetallic Fine-Grained Wires from Al-0.25\%Zr-(Sc,Hf) Alloys
}

\author{
Aleksey Nokhrin ${ }^{1, *(\mathbb{D}}$, Iana Shadrina ${ }^{1}$, Vladimir Chuvil'deev ${ }^{1} \mathbb{D}$, Vladimir Kopylov ${ }^{1,2}$, Nikolay Berendeev ${ }^{1}$, \\ Artem Murashov ${ }^{1}$, Aleksandr Bobrov ${ }^{1}$, Nataliya Tabachkova ${ }^{3,4}{ }^{\mathbb{D}}$, Elena Smirnova ${ }^{1}$ and Mikhail Faddeev $^{1}$
}

check for updates

Citation: Nokhrin, A.; Shadrina, I.; Chuvil'deev, V.; Kopylov, V.; Berendeev, N.; Murashov, A.; Bobrov, A.; Tabachkova, N.; Smirnova, E.; Faddeev, M. Investigation of Thermal Stability of Microstructure and Mechanical Properties of Bimetallic Fine-Grained Wires from $\mathrm{Al}-0.25 \% \mathrm{Zr}-(\mathrm{Sc}, \mathrm{Hf})$ Alloys. Materials 2022, 15, 185. https://doi.org/ 10.3390/ma15010185

Academic Editor:

Anastasia Mikhaylovskaya

Received: 15 November 2021

Accepted: 23 December 2021

Published: 27 December 2021

Publisher's Note: MDPI stays neutral with regard to jurisdictional claims in published maps and institutional affiliations.

Copyright: (C) 2021 by the authors. Licensee MDPI, Basel, Switzerland. This article is an open access article distributed under the terms and conditions of the Creative Commons Attribution (CC BY) license (https:// creativecommons.org/licenses/by/ $4.0 /)$.
1 Materials Science Department, Physical-Technical Research Institute, Lobachevsky State University of Nizhniy Novgorod, 603022 Nizhny Novgorod, Russia; janashadr@gmail.com (I.S.); chuvildeev@nifti.unn.ru (V.C.); kopylov.ecap@nifti.unn.ru (V.K.); ear13@mail.ru (N.B.); aamurashov@nifti.unn.ru (A.M.); aabobrov@bk.ru (A.B.); smirnova@nifti.unn.ru (E.S.); faddeev@yandex.ru (M.F.)

2 Laboratory of Vacuum Plasma Coating, Physical-Technical Institute, National Academy of Sciences of Belarus, 220141 Minsk, Belarus

3 Center Collective Use "Materials Science and Metallurgy", National University of Science and Technology "MISIS", 119991 Moscow, Russia; ntabachkova@misis.ru

4 Laboratory "FIANIT", Laser Materials and Technology Research Center, A. M. Prokhorov General Physics Institute, Russian Academy of Sciences, 119991 Moscow, Russia

* Correspondence: nokhrin@nifti.unn.ru

\begin{abstract}
Thermal stability of composite bimetallic wires from five novel microalloyed aluminum alloys with different contents of alloying elements ( $\mathrm{Zr}, \mathrm{Sc}$, and Hf) is investigated. The alloy workpieces were obtained by induction-casting in a vacuum, preliminary severe plastic deformation, and annealing providing the formation of a uniform microstructure and the nucleation of stabilizing intermetallide $\mathrm{Al}_{3}(\mathrm{Zr}, \mathrm{Sc}, \mathrm{Hf})$ nanoparticles. The wires of $0.26 \mathrm{~mm}$ in diameter were obtained by simultaneous deformation of the $\mathrm{Al}$ alloy with $\mathrm{Cu}$ shell. The bimetallic wires demonstrated high strength and improved thermal stability. After annealing at $450-500{ }^{\circ} \mathrm{C}$, a uniform fine-grained microstructure formed in the wire (the mean grain sizes in the annealed $\mathrm{Al}$ wires are 3-5 $\mu \mathrm{m}$ ). An increased hardness and strength due to nucleation of the $\mathrm{Al}_{3}(\mathrm{Sc}, \mathrm{Hf})$ particles was observed. A diffusion of $\mathrm{Cu}$ from the shell into the surface layers of the $\mathrm{Al}$ wire was observed when heating up to $400-450{ }^{\circ} \mathrm{C}$. The $\mathrm{Cu}$ diffusion depth into the annealed $\mathrm{Al}$ wire surfaces reached $30-40 \mu \mathrm{m}$. The maximum elongation to failure of the wires (20-30\%) was achieved after annealing at $350{ }^{\circ} \mathrm{C}$. The maximum values of microhardness $\left(\mathrm{H}_{\mathrm{V}}=500-520 \mathrm{MPa}\right)$ and of ultimate strength $\left(\sigma_{\mathrm{b}}=195-235 \mathrm{MPa}\right)$ after annealing at $500{ }^{\circ} \mathrm{C}$ were observed for the wires made from the $\mathrm{Al}$ alloys alloyed with $0.05-0.1 \%$ Sc.
\end{abstract}

Keywords: aluminum alloys; microalloying; microhardness; electrical conductivity; zirconium; scandium; hafnium

\section{Introduction}

The replacement of copper wires by aluminum ones is one of the relevant problems of modern aviation electrical engineering [1-3]. This would allow reducing the weight of the on-board electrical wiring of modern aircrafts at the same as increasing thermal stability, high electrical conductivity, and strength at elevated temperatures [4,5].

At present, complex $\mathrm{Al}$ alloys are the most promising material for the bimetallic wires of the types 55A, 55M, 55PC0811 (Spec-55), EN 2714-013A, etc. with Cu or Ag coatings. Complex Al-Ce-La-Fe Russian industrial alloy 01,417 is an example of such materials [4] as well as a number of novel conductor alloys that are doped with rare earth elements (REE) [6-12]. The 01,417 alloy has the minimal ultimate strength of $160 \mathrm{MPa}$, relative elongation to failure $8 \%$, and specific electrical resistivity (SER) of $3.2 \mu \Omega \cdot \mathrm{cm}$ [4]. Al wires of $0.2-0.3 \mathrm{~mm}$ in diameter with $\mathrm{Cu}$ or $\mathrm{Ni}$ coatings are being fabricated from this alloy [4]. 
Note that the wires that are made from 01,417 [4] иalloy of the known conductor Al-Mg-Si alloy family $[1,5,13,14]$ don't have the necessary thermal stability to allow replacing smallsized $\mathrm{Cu}$ wires efficiently. The requirements of the thermal stability of the structure and properties during long-term (several thousand hours) operation at $200-250{ }^{\circ} \mathrm{C}$ are imposed on modern aviation wires. In this connection, the novel conductor dispersion-hardened $\mathrm{Al}$ alloys are being developed intensively. The improved strength and thermal stability in these alloys are provided by the nucleation of $\mathrm{Al}_{3} \mathrm{X}$ nanoparticles where $\mathrm{X}=\mathrm{Sc}, \mathrm{Zr}$, $\mathrm{Er}$, and other alloying elements [15-25]. The alloying of the Al alloys by Sc is the most efficient $[16,21,24,25]$. It allows the ensuring of the high strength and thermal stability of the microstructure of the $\mathrm{Al}$ alloys. Sc is one of the most expensive alloying elements for the $\mathrm{Al}$ alloys. Therefore, the replacement of Sc by cheaper transition metals and/or REEs ( $\mathrm{Zr}, \mathrm{Er}, \mathrm{Hf}$, etc.) is an important practical task [15-25].

At present, the conductor Al-Zr alloys are being developed intensively [26-29]. In spite of prospects of the $\mathrm{Al}-\mathrm{Zr}$ system in electrical engineering applications, the low nucleation intensity of the $\mathrm{Al}_{3} \mathrm{Zr}$ particles is a drawback of these alloys. The intensive nucleation of these particles takes place at high temperatures only (over $400-450{ }^{\circ} \mathrm{C}$ ) and isothermic holding times (over $50 \mathrm{~h}$ ) [26-30]. Note also that the decomposition of solid solutions in the $\mathrm{Al}-\mathrm{Zr}$ and Al-Sc alloys may go via an intermittent precipitation mechanism with formation of large enough particles [21,30]. The complexity of these factors doesn't allow stabilizing the ultrafine-grained (UFG) microstructure in $\mathrm{Al}$ since the grain boundaries in $\mathrm{Al}$ begin to migrate at $200-250{ }^{\circ} \mathrm{C}$ [31].

To solve this problem, two main approaches are applied at present. The first approach is the development of alloys with improved $\mathrm{Zr}$ content (0.4-0.6\% $\mathrm{Zr}$ [26-29]) where the $\mathrm{Zr}$ concentration is much higher than the solubility limit of $\mathrm{Zr}$ in $\mathrm{Al}$ with the simultaneous application of ultrafast crystallization technology. This approach is hardly applicable for making the wires with small diameters since the primary large $\mathrm{Al}_{3} \mathrm{Zr}$ particles may lead to the wire breaking during drawing at room temperature or while rolling. The second approach is the development of Al-Zr alloys that are doped additionally by a third element affecting the Al-Zr alloy precipitation intensity. According to [5,16,24,25,32-34], the additional alloying of $\mathrm{Al}-\mathrm{Zr}$ alloy by some rare elements (REE) or transition metals (Sc, Hf, $\mathrm{Yb}$, Er, etc.) would lead to the accelerated nucleation of $\mathrm{Al}_{3} \mathrm{Zr}$ intermetallide nanoparticles, which should ensure the stabilization of the nonequilibrium UFG microstructure.

The present study was aimed at the fabrication and investigation of the thermal stability of the small-sized composite wires that were fabricated from novel dispersionhardened microalloyed $\mathrm{Al}$ alloys; the $\mathrm{Al}-0.25 \% \mathrm{Zr}$ alloys were the objects of investigation. The accelerated nucleation of the $\mathrm{Al}_{3} \mathrm{Zr}$ particles with the $\mathrm{L} 1_{2}$ structure was provided by adding $0.05-0.1 \%$ of Sc and Hf.

\section{Materials and Methods}

The microalloyed $\mathrm{Al}$ alloys (Table 1 ) and the bimetallic $\mathrm{Al}$ wires of $0.26 \mathrm{~mm}$ in diameter that were obtained from these alloys with high-purity $\mathrm{Cu}$ coatings $(\sim 30 \mu \mathrm{m}$ thick) were the objects of investigation. An example of cross-sections of the bimetallic wires is presented in Figure 1.

Table 1. The composition and mechanical properties of conductor $\mathrm{Al}$ alloys.

\begin{tabular}{|c|c|c|c|c|c|c|c|}
\hline \multirow{3}{*}{ Alloy } & \multirow{2}{*}{\multicolumn{3}{|c|}{ Alloying Elements Contents in the Alloy, wt.\% }} & \multicolumn{4}{|c|}{ Mechanical Properties of the Wire } \\
\hline & & & & \multicolumn{2}{|c|}{ Initial State } & \multicolumn{2}{|c|}{ After Annealing at $450^{\circ} \mathrm{C}, 30 \mathrm{~min}$} \\
\hline & $\mathrm{Zr}$ & Sc & Hf & $\mathrm{H}_{\mathrm{v}}, \mathrm{MPa}$ & $\sigma_{\mathrm{b}}, \mathrm{MPa}$ & $\mathrm{H}_{\mathrm{v}}, \mathrm{MPa}$ & $\sigma_{\mathrm{b}}, \mathrm{MPa}$ \\
\hline$\# 1$ & - & - & - & 300 & 230 & 270 & 135 \\
\hline \#2 & 0.25 & - & - & 465 & 320 & 295 & 150 \\
\hline \#3 & 0.25 & 0.10 & - & 625 & 345 & 510 & 235 \\
\hline$\# 4$ & 0.25 & - & 0.10 & 540 & 370 & 445 & 180 \\
\hline$\# 5$ & 0.25 & 0.05 & 0.05 & 565 & 370 & 500 & 195 \\
\hline$\# 6$ & 0.20 & 0.10 & 0.10 & 605 & 350 & 520 & 210 \\
\hline
\end{tabular}




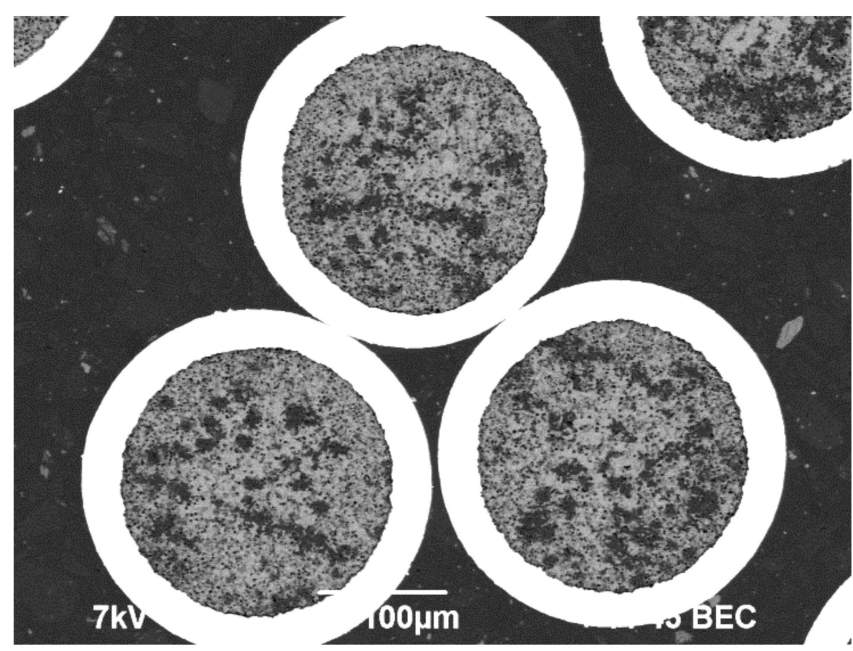

Figure 1. Cross-sections of the bimetallic wires. Scanning electron microscope (SEM).

The wires made from pure Al A99 (Alloy \#1) and Alloy \#6 with a reduced Zr content $(0.20 \%)$ and increased $(0.1 \%)$ Sc while the Hf contents were used as the reference objects.

The $\mathrm{Al}$ workpieces of $22 \times 22 \mathrm{~mm}^{2}$ in cross-sections were obtained by inductioncasting from high-purity Al A99 using an INDUTHERM ${ }^{\circledR}$ VTC-200 casting machine (Indutherm $\mathrm{GmbH}$, Walzbachtal, Germany). The regimes of making the bulks are presented in Table 2. The uncertainty of the temperature measurements in the casting machine was $10{ }^{\circ} \mathrm{C}$. The choice of the casting regimes was based on the analysis of our previous experiments on preparing the conductor $\mathrm{Al}$ alloys. In these regimes, a minimal quantity of the primary particles forms during crystallization and the cast alloy workpieces have the same macrostructure and close properties (microhardness, SER) in different bulk cross-sections. For alloying the alloys, $\mathrm{Al}-2 \% \mathrm{Zr}, \mathrm{Al}-2 \% \mathrm{Sc}$, and $\mathrm{Al}-2 \% \mathrm{Hf}$ master alloys that were obtained by induction casting followed by rolling into foils of $0.2 \mathrm{~mm}$ in thickness were used. The foil that was obtained was cut into fragments of $\sim 1 \mathrm{~mm}^{2}$ in size and were mixed with $\mathrm{Al}$ in preset proportions.

Table 2. The preparation regimes of the alloys.

\begin{tabular}{|c|c|c|c|c|c|c|}
\hline Parameters & Alloy \#1 & Alloy \#2 & Alloy \#3 & Alloy \#4 & Alloy \#5 & Alloy \#6 \\
\hline \multicolumn{7}{|c|}{ Preparation of the cast alloys } \\
\hline Mold, mm & \multirow{2}{*}{\multicolumn{6}{|c|}{$\begin{aligned} 22 \times 22 \times 160, \text { graphite } \\
\mathrm{SiO}_{2}+\mathrm{ZrO}_{2}\end{aligned}$}} \\
\hline Crucible $150 \mathrm{~cm}^{3}$ & \multirow{2}{*}{\multicolumn{6}{|c|}{$\begin{array}{c}\mathrm{SiO}_{2}+\mathrm{ZrO}_{2} \\
3\end{array}$}} \\
\hline Ar purge prior to casting, cycles & & & & & & \\
\hline Ar purge during heating, cycles & \multicolumn{6}{|c|}{3} \\
\hline Melt mixing & \multirow{2}{*}{\multicolumn{6}{|c|}{$\begin{array}{l}\text { Induction casting } \\
4.5\end{array}$}} \\
\hline Heating power, kW & & & & & & \\
\hline Time until melting of the components, $\mathrm{s}$ & 520 & 510 & 515 & 510 & 515 & 480 \\
\hline Melt holding temperature, ${ }^{\circ} \mathrm{C}$ & 780 & 810 & 820 & 820 & 820 & 820 \\
\hline Holding before pouring, $\min$ & 3 & 9 & 20 & 20 & 20 & 20 \\
\hline Pouring temperature, ${ }^{\circ} \mathrm{C}$ & \multicolumn{6}{|c|}{760} \\
\hline $\begin{array}{l}\text { Cooling time, s } \\
\text { incl. vibration time, } s\end{array}$ & 50 & \multirow{2}{*}{\multicolumn{4}{|c|}{$\begin{array}{c}50 \\
\text { thes }\end{array}$}} & 250 \\
\hline \multicolumn{6}{|c|}{ Deformation processing of the cast workpieces and wire making } & \\
\hline $\begin{array}{l}\text { Deformation processing of the cast } \\
\text { workpieces }\end{array}$ & \multicolumn{6}{|c|}{$\operatorname{ECAP}\left(\mathrm{N}_{\mathrm{ECAP}}=4, \mathrm{~T}_{\mathrm{ECAP}}=250^{\circ} \mathrm{C}\right)$} \\
\hline Temperature of 2 -h annealing, ${ }^{\circ} \mathrm{C}$ & 300 & 300 & 400 & 400 & 400 & 400 \\
\hline $\begin{array}{l}\text { Workpiece processing } \\
\text { Wire making }\end{array}$ & \multicolumn{6}{|c|}{$\begin{array}{l}\text { Milling, scalping } \\
\text { Rolling in rolls at room temperature }\end{array}$} \\
\hline
\end{tabular}

After casting, the $\mathrm{Al}$ alloy workpieces were subjected to equal channel angular pressing (ECAP) at $250{ }^{\circ} \mathrm{C}$ (the number of pressing cycles $n=4$, mode $B_{c}$ ) to remove the microstructure non uniformities. The selected ECAP temperature provided (i) the absence of microand macro-cracks in the $\mathrm{Al}$ alloy workpieces, (ii) forming a uniform fine-grained structure 
in the $\mathrm{Al}$ alloys; and (iii) the absence of nucleation of the $\mathrm{Al}_{3}(\mathrm{TM}, \mathrm{REE})$ particles in the course of ECAP. ECAP was performed using a Ficep ${ }^{\circledR}$ HF 400 L hydraulic press (Ficep ${ }^{\circledR}$ S.P.A., Varese, Italy). The workpieces that were obtained by ECAP were annealed in EKPS-10 air furnace (Smolensk SKTB SPU JSC, Smolensk, Russia) at $300-400{ }^{\circ} \mathrm{C}(2 \mathrm{~h})$ to form a uniform recrystallized microstructure and for nucleating the $\mathrm{Al}_{3} \mathrm{X}$ particles providing the stability of the fine-grained structure of the alloys. The uncertainty of the temperature maintenance in the furnace was $10{ }^{\circ} \mathrm{C}$. After annealing, the workpiece surfaces were scalped to remove the oxides. The sample bimetallic wires were obtained by rolling of the $\mathrm{Al}$ workpieces with $\mathrm{Cu}$ cladding in cylindrical rolls at room temperature. High-purity $\mathrm{Cu}$ (Russian industrial name M00k) was used as the cladding material.

The chemical analysis was performed using iCAP ${ }^{\circledR} 6300-\mathrm{ICP}-\mathrm{OES}$ Radial View ${ }^{\mathrm{TM}}$ spectrometer with induction-coupled plasma (Thermo Scientific, Waltham, MA, USA). The microstructure investigations were performed using a Leica ${ }^{\circledR}$ IM DRM metallographic optical microscope (Leica Microsystems GmbH, Wetzlar, Germany), Jeol ${ }^{\circledR}$ JSM-6490 scanning electron microscope (SEM) (Jeol Ltd., Tokyo, Japan) that was equipped with Oxford Instruments ${ }^{\circledR}$ INCA 350 energy dispersion spectrometer (EDS) (Oxford Instruments pls., Oxford, UK), and a Jeol ${ }^{\circledR}$ JEM-2100 transmission electron microscope (TEM) (Jeol Ltd., Tokyo, Japan). For convenience of the microstructure investigations, the sample wires were pressed into WEM REM mixture (Cloeren Technology GmbH, Berlin, Germany) or into an epoxy cement; the polymerization temperature of which didn't exceed $150{ }^{\circ} \mathrm{C}$, the polymerization time was $10 \mathrm{~min}$ or less. Low polymerization temperatures and times allowed avoiding any effect of this process on the microstructure parameters and on the mechanical properties of the wires.

The microhardness $\mathrm{H}_{\mathrm{v}}$ was measured in the centers of the wire cross-sections using a Qness ${ }^{\circledR}$ A60+ microhardness tester (Qness GmbH, Golling, Austria) with the load of $20 \mathrm{~g}$. The uncertainty of the hardness measurements was $\pm 20 \mathrm{MPa}$. For the tear tests, Lloyd Instruments ${ }^{\circledR}$ LR5K Plus universal breaking machine (Lloyd Instruments Ltd., West Sussex, UK) was used. The traverse travel speed was $10 \mathrm{~mm} / \mathrm{min}$. The $60 \mathrm{~mm}$ long sample wires were tested at room temperature according to Russian Standard GOST 10446-80 [35]. In the course of testing, "stress $\sigma$-strain $\varepsilon$ " curves were recorded which the values of the ultimate strength $\sigma_{\mathrm{b}}$ and of relative elongation to failure $\delta$ were determined from. To obtain statistically reliable results, three samples or more were tested in each series. The mean uncertainty of the ultimate strength measurements was $\pm 20 \mathrm{MPa}$. The fractographic investigations of the sample wire fractures after the tension tests were carried out using a TESCAN ${ }^{\circledR}$ Vega $^{\mathrm{TM}}$ II SEM (Tescan Orsay Holding, a.s., Brno, Czech Republic).

For the SER measurements by the eddy current method in the cast and fine-grained bulk alloys, a SIGMATEST ${ }^{\circledR} 2.069$ instrument (FOERSTER Int., Pittsburgh, PA, USA) was used. The uncertainty of the SER measurements was $\pm 0.03 \mu \Omega \cdot \mathrm{cm}$. To measure the SER of the wires, an E7-8 digital L-C-R meter (KIP Etalon, Korolev, Russia) that allowed the measurement of the SER of wires with an uncertainty $\pm 0.1 \mu \Omega \cdot \mathrm{cm}$ was employed. The SER was measured on $0.6 \mathrm{~m}$ long sample wires. The cross-section areas of the wires were measured at three points with an uncertainty of $10 \mu \mathrm{m}$.

To study the thermal stability of the sample wires, they were subjected to $30 \mathrm{~min}$ annealing in ambient air using an EKPS-10 furnace. The uncertainty of the temperature maintenance was $10^{\circ} \mathrm{C}$.

\section{Results}

\subsection{Investigation of the Alloys}

The investigations that were performed have shown that the Sc concentration decreased during casting by $0.005-0.01 \mathrm{wt} . \%$ relative to the calculated one. The $\mathrm{Zr}$ and $\mathrm{Hf}$ concentrations matched the ones that were specified in Table 1. No oxide particle formation was observed by SEM methods.

The cast alloys in the initial state had a uniform coarse-grained structure consisting of columnar crystallites. At the sides of the cast bulks with the addition of $0.1 \%$ Sc (Alloy 
\#3) or $0.1 \% \mathrm{Hf}$ (Alloy \#4), a columnar crystallite structure was observed compared with the central parts of the ones that consisted of uniaxial grains of $\sim 280 \mu \mathrm{m}$ in size (Figure 2c,d). The ratio of the areas that were occupied by each type of structure depended, first of all, on the type and concentration of the alloying elements. The macrostructures of Alloys \#5 (Al-0.25\%Zr-0.05\%Sc-0.05\%Hf) and \#6 (Al-0.20\%Zr-0.1\%Sc-0.1\%Hf) were the same and comprised large columnar crystals that were oriented from the bulk edges towards the centers. (Figure 2e,f) This means that the co-alloying with Sc and Hf were less efficient for the grinding of the cast Al macrostructure. In all the alloys, the primary Zr-containing particles were observed in the form of separate inclusions of $\sim 1-3 \mu \mathrm{m}$ in size as well as of aggregates of the micrometer-sized particles (Figure 2e).

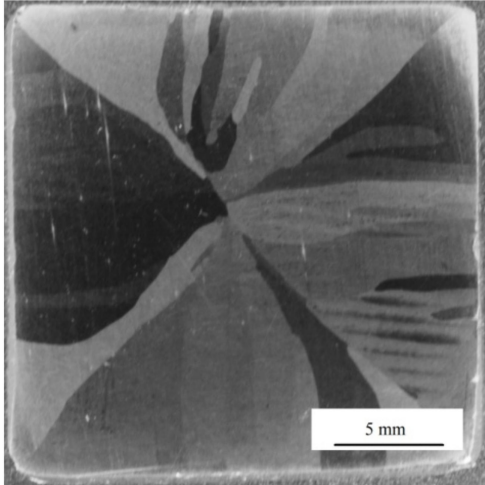

(a)

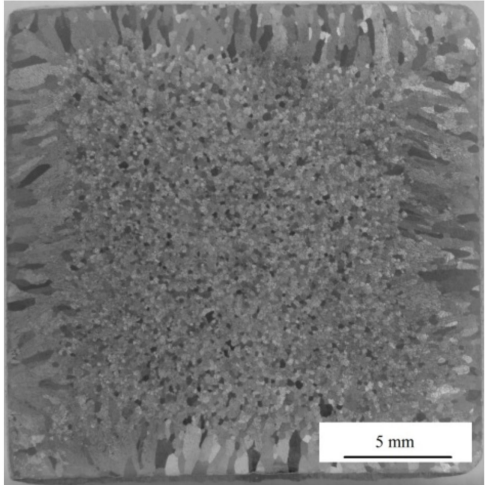

(d)

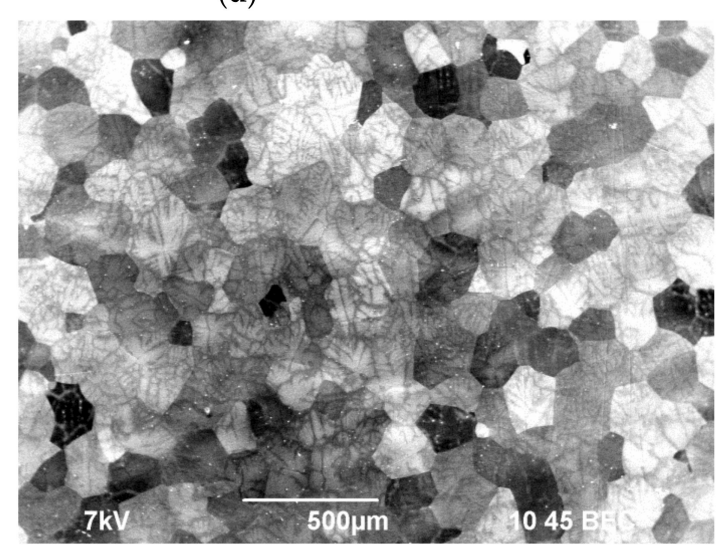

(g)

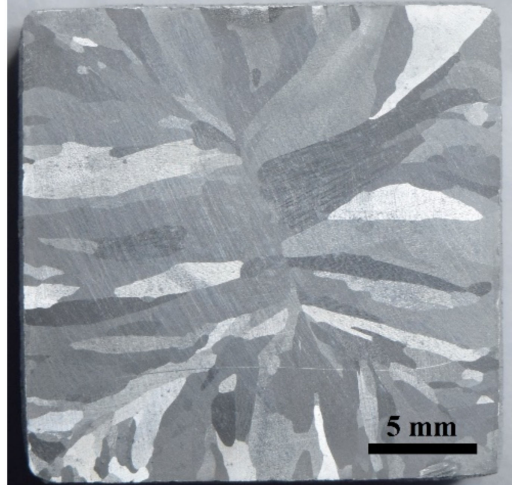

(b)

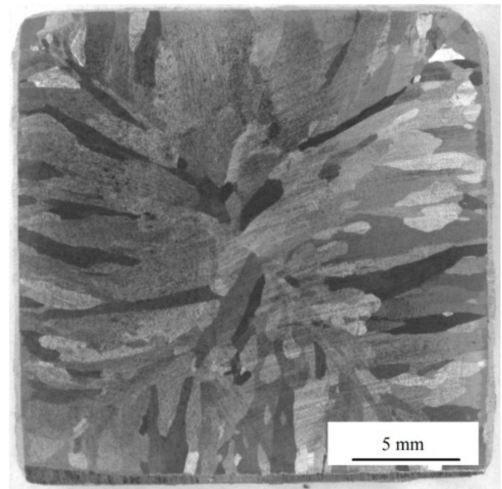

(e)

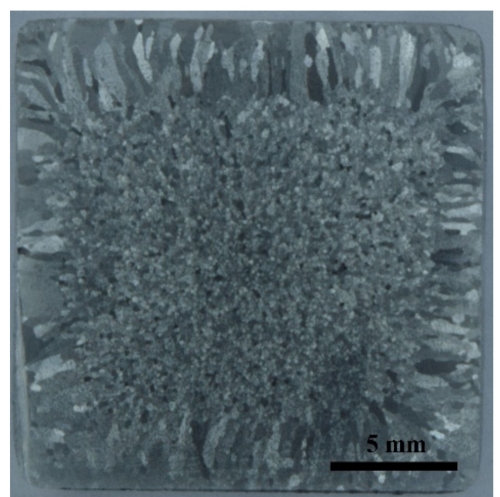

(c)

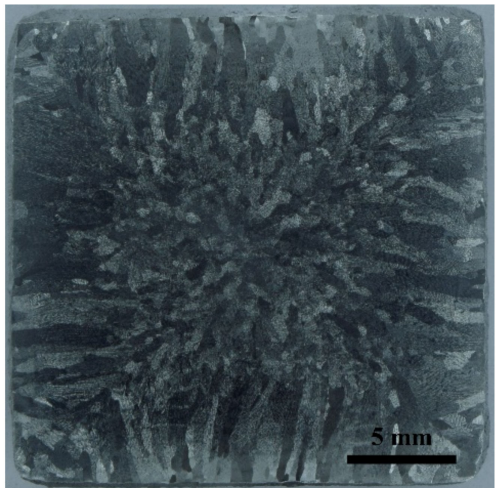

(f)

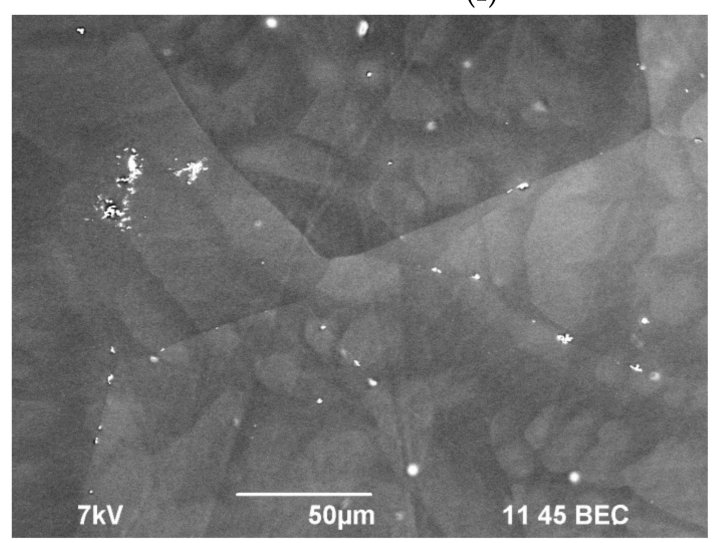

(h)

Figure 2. The microstructure of the cast alloys: (a) Alloy \#1; (b) Alloy \#2; (c) Alloy \#3; (d) Alloy \#4; $(\mathbf{e}, \mathbf{g}, \mathbf{h})$ Alloy \#5; and (f) Alloy \#6. (g) The microstructure in the center of the bulk for Alloy \#4; (h) the $\mathrm{Al}_{3} \mathrm{Zr}$ particles nucleated in the center of the bulk for Alloy \#2. 
The SER and microhardness of the alloys \#1-6 in the initial state were $2.65 \mu \Omega \cdot \mathrm{cm}$ and $200 \mathrm{MPa}$ (Alloy \#1), $2.87 \mu \Omega \cdot \mathrm{cm}$ and $275 \mathrm{MPa}$ (Alloy \#2), $3.43 \mu \Omega \cdot \mathrm{cm}$ and $350 \mathrm{MPa}$ (Alloy \#3), $3.36 \mu \Omega \cdot \mathrm{cm}$ and $345 \mathrm{MPa}$ (Alloy \#4), $3.39 \mu \Omega \cdot \mathrm{cm}$ and $315 \mathrm{MPa}$ (Alloy \#5), and $3.46 \mu \Omega \cdot \mathrm{cm}$ and $340 \mathrm{MPa}$ (Alloy \#6), respectively.

After ECAP, the $\mathrm{Al}$ alloy workpieces were subjected to $2 \mathrm{~h}$ annealing in the temperature range from 300 to $400{ }^{\circ} \mathrm{C}$ to ensure a uniformly recrystallized microstructure and to remove the dendrite nonuniformity (see Figure $2 \mathrm{a}-\mathrm{c}$ ), and to achieve the SER magnitude of the alloys $3.0 \mu \Omega \cdot \mathrm{cm}$ or less. After annealing and $400{ }^{\circ} \mathrm{C}(2 \mathrm{~h})$, a uniform microstructure was formed in the alloys \#3 and 4 with the grain sizes $\sim 150-200 \mu \mathrm{m}$ (Figure 3a) and $\sim 200 \mu \mathrm{m}$ (Figure $3 b$ ), respectively. The mean grain sizes in alloys \#5 and \#6 containing Sc and Hf simultaneously were $\sim 0.5-1 \mathrm{~mm}$. The magnitudes of SER in the annealed alloys \#2-6 were $2.92-2.95 \mu \Omega \cdot \mathrm{cm}$.

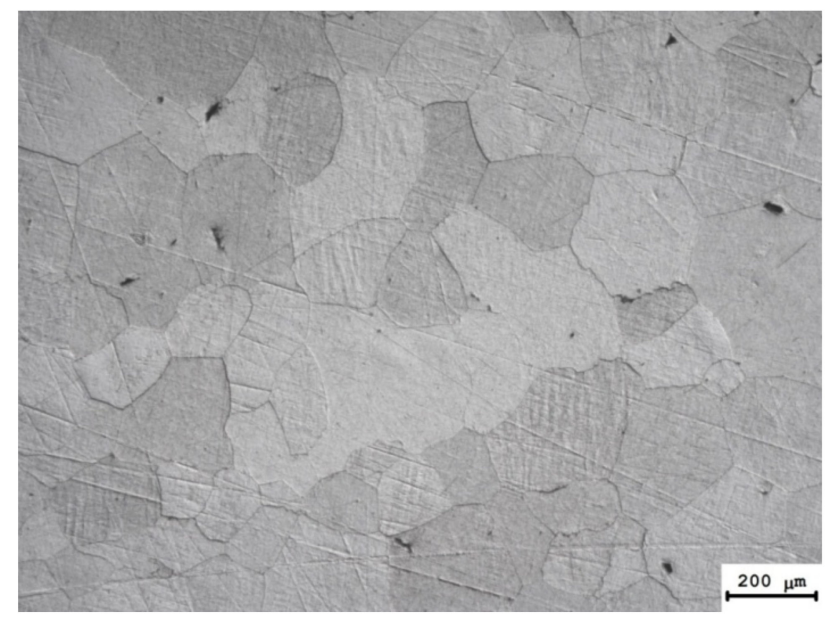

(a)

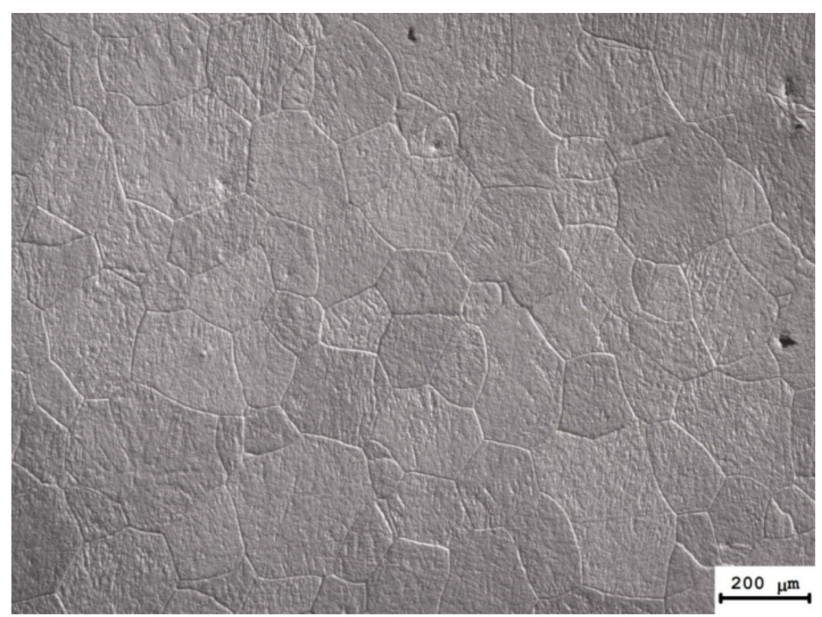

(b)

Figure 3. The microstructure of alloys after ECAP and annealing at $400{ }^{\circ} \mathrm{C}$ for $2 \mathrm{~h}$ : (a) Alloy \#3; (b) Alloy \#4. Metallography.

In alloys \#1 and \#2 (in which the magnitude of SER didn't exceed $3.0 \mu \Omega \cdot \mathrm{cm}$ ) a uniform recrystallized microstructure formed after annealing at $300{ }^{\circ} \mathrm{C}(2 \mathrm{~h})$. The mean grain sizes in the annealed alloys \#1 and \#2 were $0.5-1 \mathrm{~mm}$, the magnitudes of SER were 2.66 and $2.84 \mu \Omega \cdot \mathrm{cm}$, respectively.

\subsection{Investigation of the Wires}

The bimetallic wires in the initial state had a strongly deformed mixed grainedsubgrained microstructure with mean fragment sizes less than $0.5 \mu \mathrm{m}$ (Figure 4 ). No essential differences in the microstructure of the wires that made from the alloys with different compositions were observed. There were the $\mathrm{Al}_{3}(\mathrm{Sc}, \mathrm{X})$ particles that were up to 20-30 $\mathrm{nm}$ in size inside the grains as well as at the grain boundaries in the Sc-containing alloys (Figure 5a,b). All the particles had regular, round shapes. No particle nucleation via intermittent decomposition was observed. Note that the selected particles were only observed in the dark field (Figure 5c,d). This was probably because the large particles were not coherent anymore so that the reflections from the ones were not manifested in the dark-field TEM images. No nanoparticle nucleation was observed in the wire that was made from Alloy \#2 (Al-0.25\%Zr) in the initial state. 


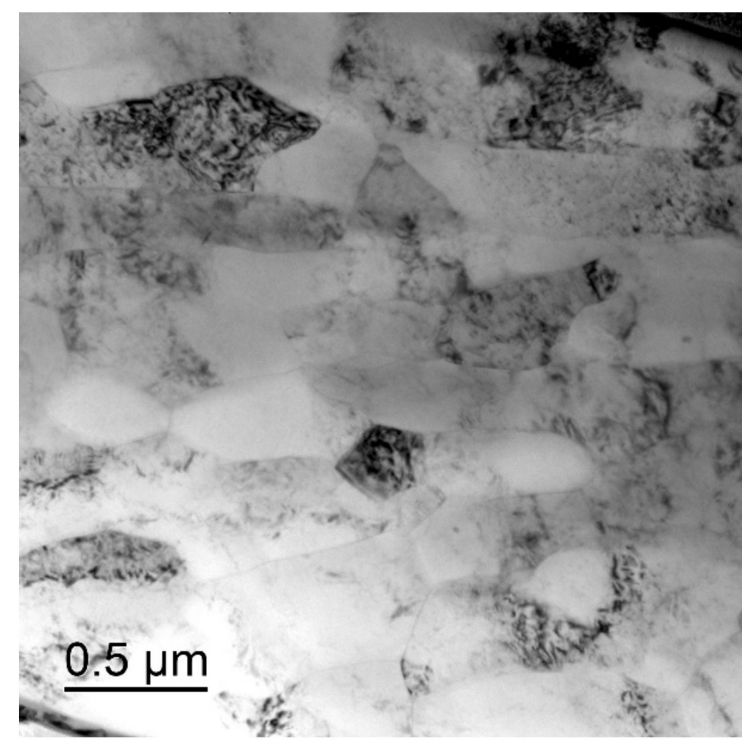

(a)

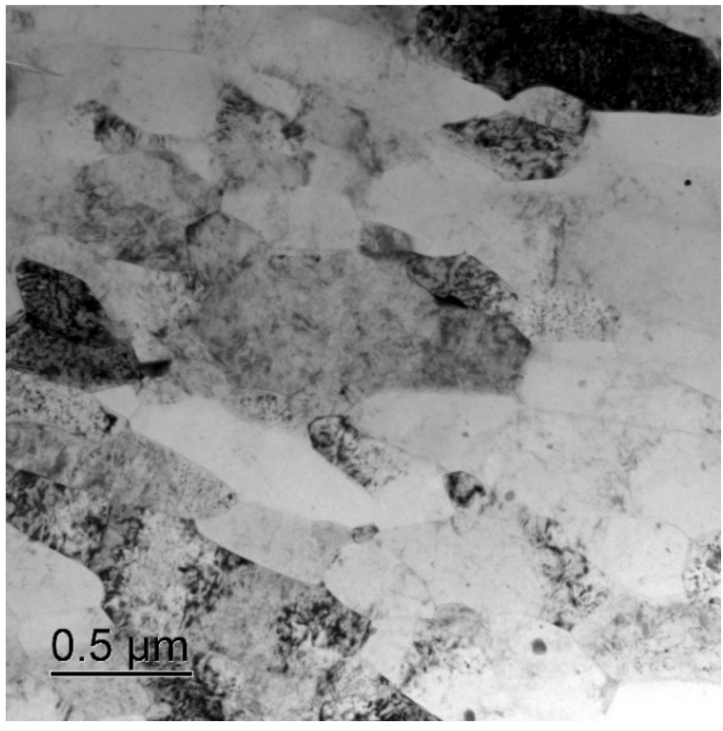

(c)

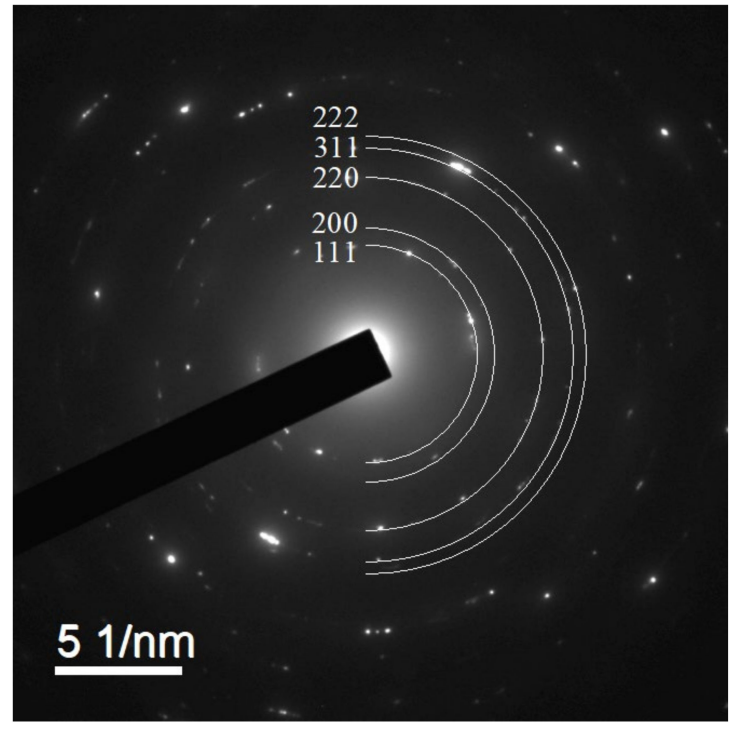

(b)

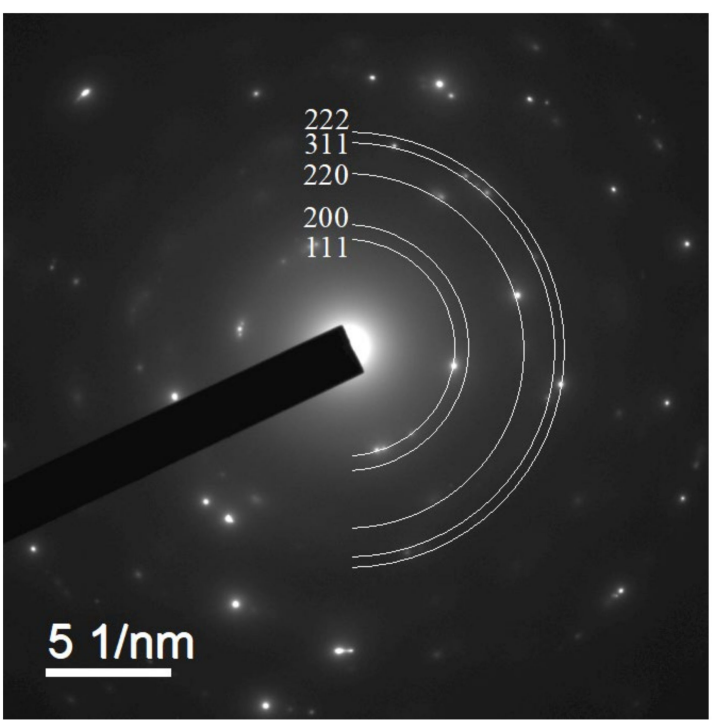

(d)

Figure 4. Microstructure of the central part of a bimetallic wire that was made from Alloy \#2 $(\mathbf{a}, \mathbf{b})$ and Alloy \#3 (c,d): (a,c) general view; (b,d) electron diffraction pattern. Transmission electron microscope (TEM).

The investigations of the $\mathrm{Cu}$ cladding by electron microscopy demonstrated the amorphization of $\mathrm{Cu}$ to take place at the interface with an $\mathrm{Al}$ core as a result of severe plastic deformation; no characteristic reflections were observed in the electron diffraction pattern of the $\mathrm{Al} / \mathrm{Cu}$ interphase boundary (Figure $6 \mathrm{~b}$ ) whereas all the reflections corresponding to the $\mathrm{Al}$ and $\mathrm{Cu}$ FCC phases were present in the electron diffraction patterns that were taken directly from the $\mathrm{Al}$ core (Figure $6 \mathrm{c}$ ) and from the $\mathrm{Cu}$ cladding (Figure 6d), respectively. 


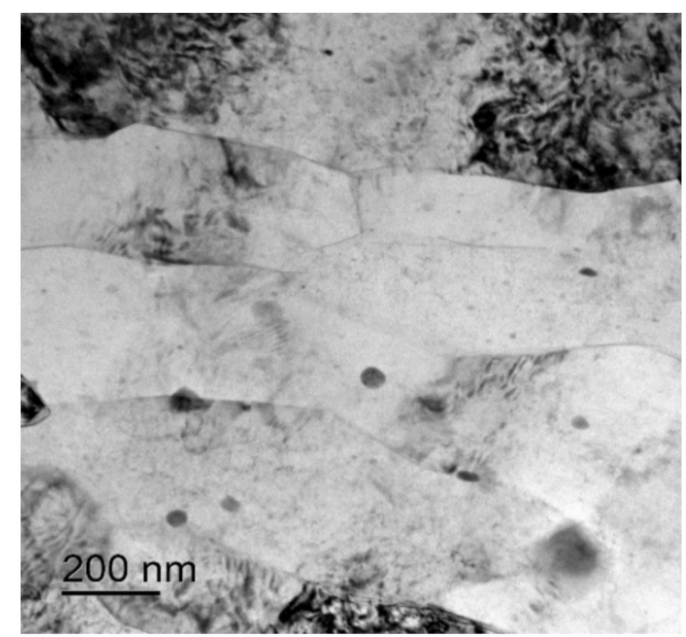

(a)

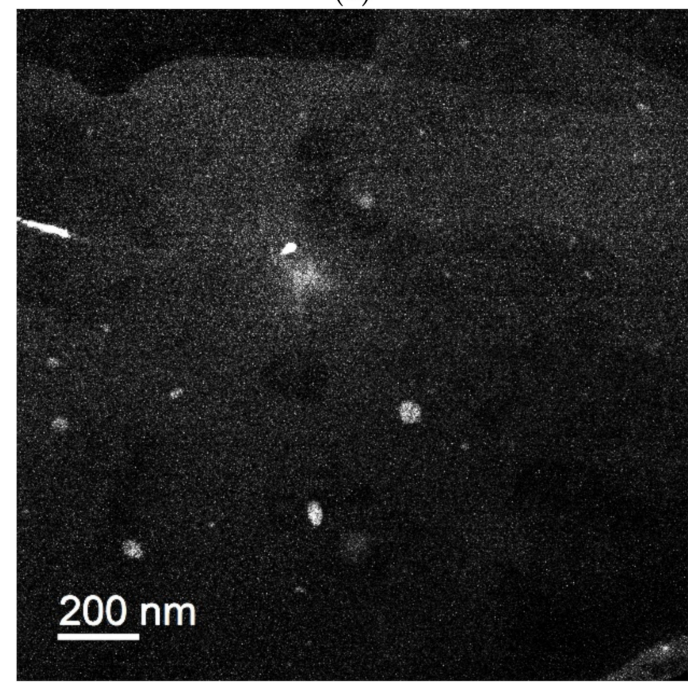

(c)

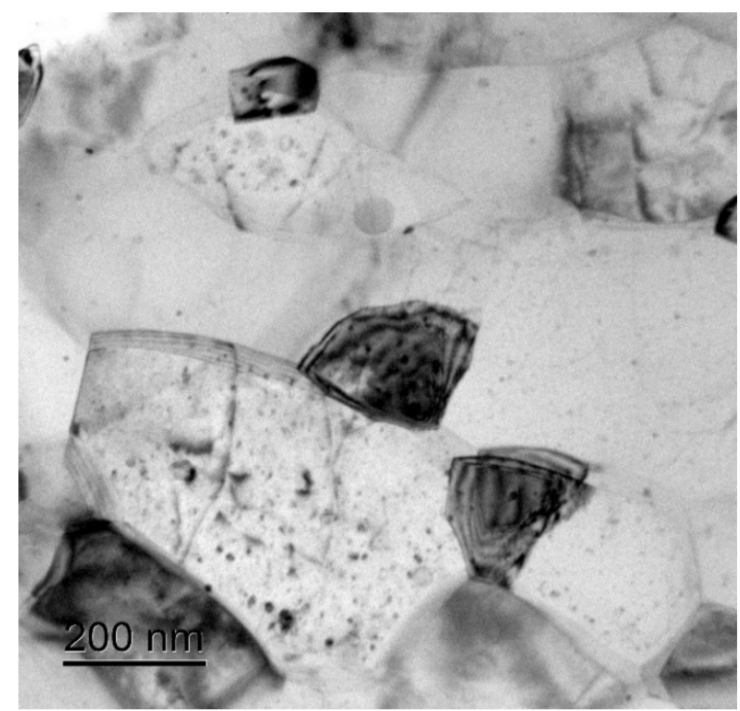

(e)

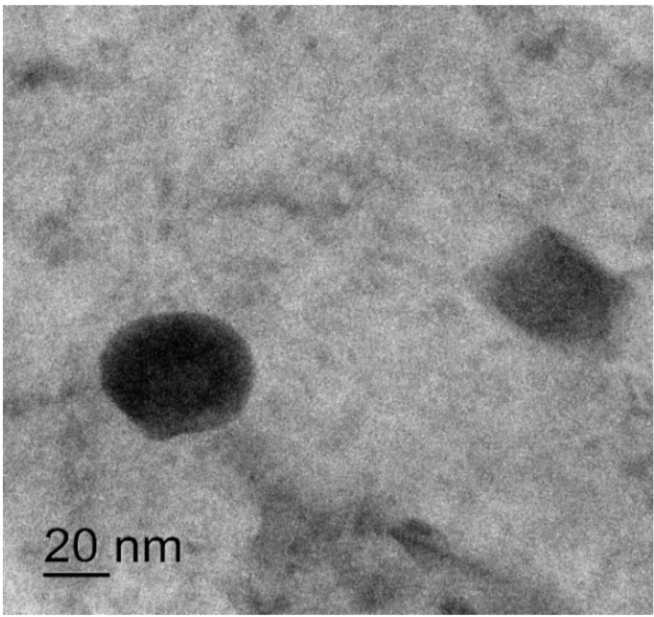

(b)

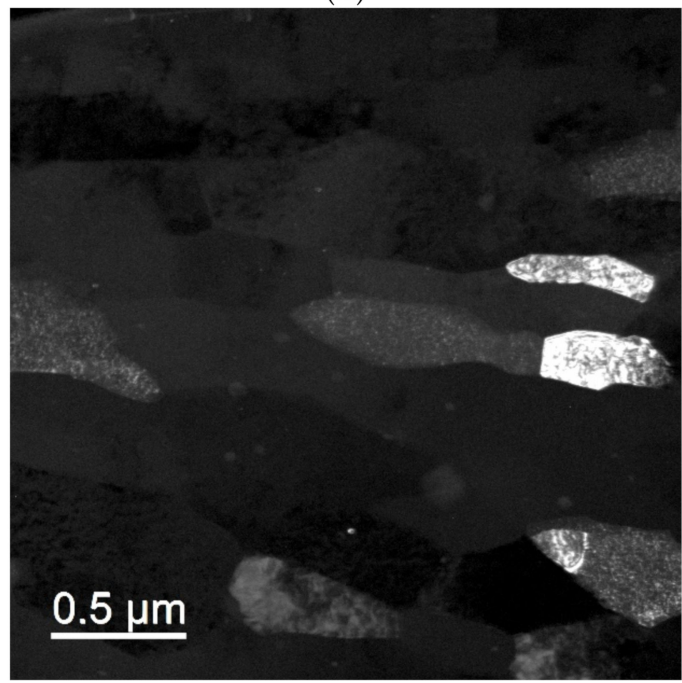

(d)

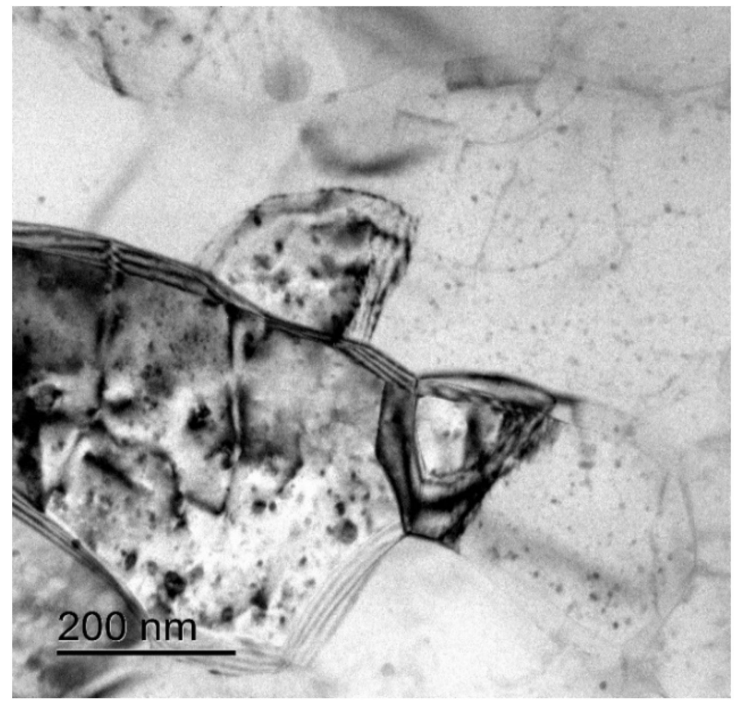

$(\mathbf{f})$

Figure 5. $\mathrm{Al}_{3}(\mathrm{Zr}, \mathrm{Sc})$ nanoparticles in the central part $(\mathbf{a}-\mathbf{d})$ and near the interphase boundary $\mathrm{Al}-\mathrm{Cu}$ $(\mathbf{e}, \mathbf{f})$ of the sample bimetallic wire that was made from Alloy \#3: (a,b) bright-field images; (c,d) darkfield images of different areas. TEM. 


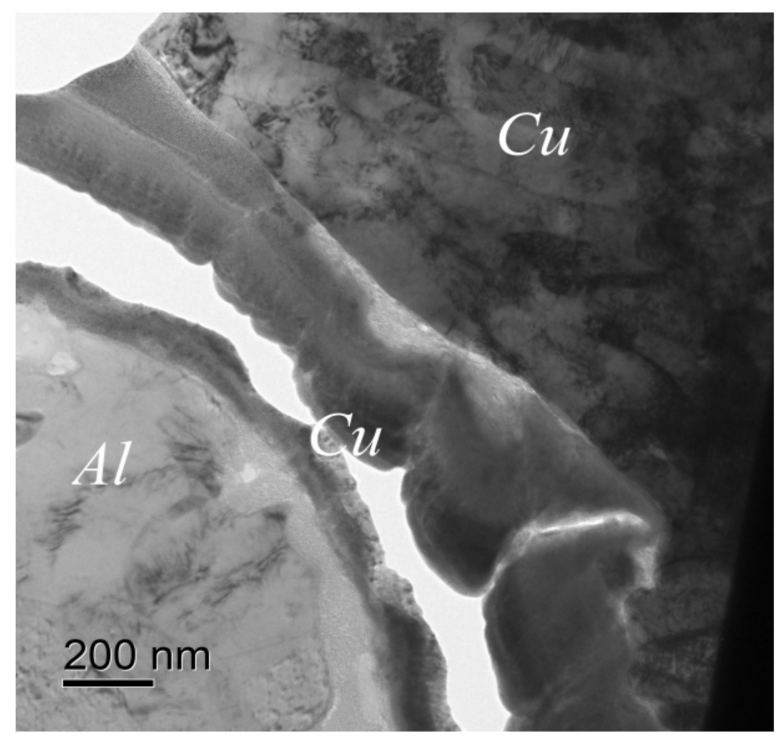

(a)

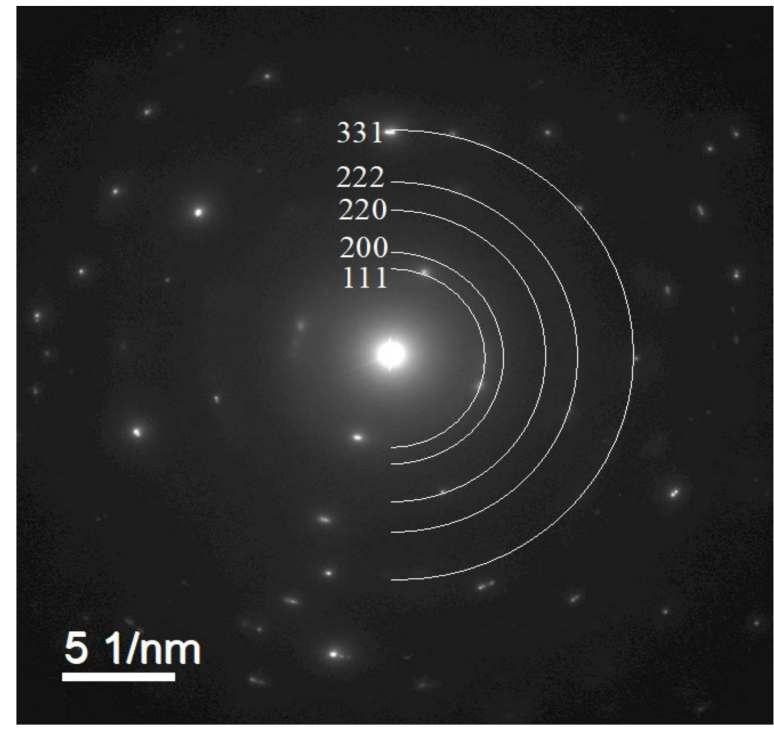

(c)

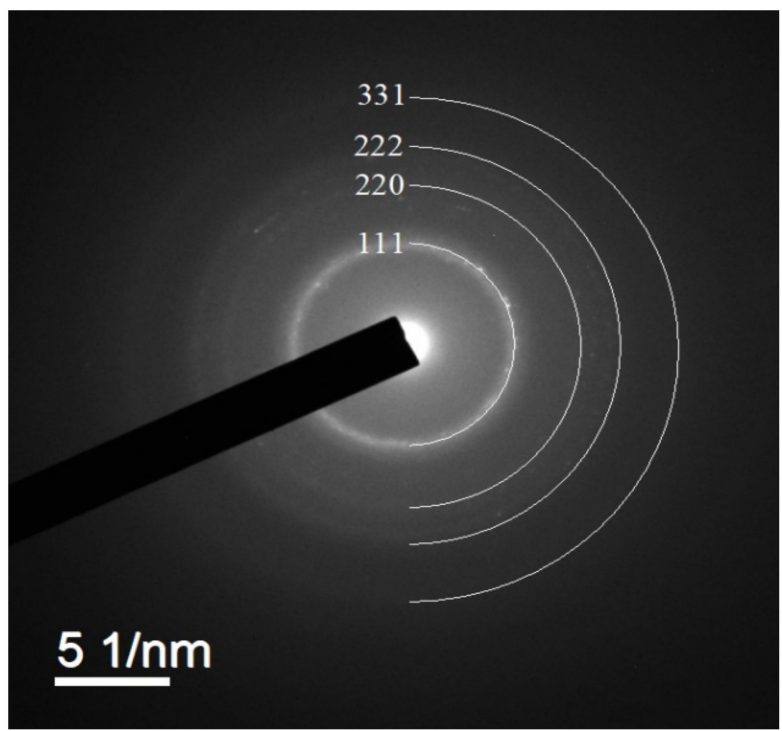

(b)

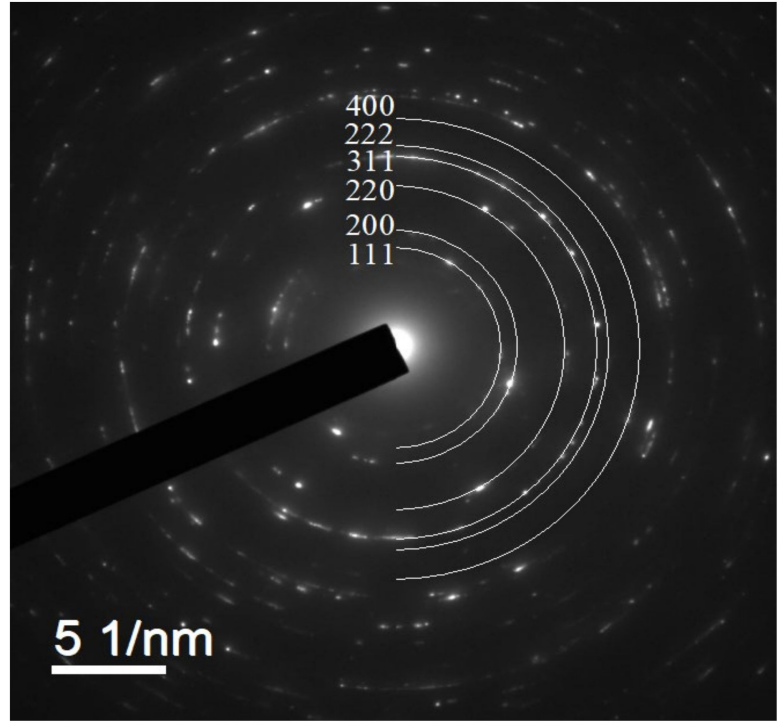

(d)

Figure 6. The results of TEM investigations of the interphase boundary " $\mathrm{Al}$ wire- $\mathrm{Cu}$ " in the initial state after rolling. Alloy \#2: (a) general view of the investigated area (a crack formed that along the $\mathrm{Al}-\mathrm{Cu}$ interphase boundary in the course of preparation of a thin foil for electron microscopy investigations is visible in Figure 6a. The presence of such cracks is an artifact of sample preparation. No interphase boundary destruction was found when investigating the polished samples by SEM). (b) The electron diffraction pattern of the interphase boundary $\mathrm{Al}-\mathrm{Cu}$; (c) electron diffraction pattern of the $\mathrm{Al}$ wire; (d) the same of the $\mathrm{Cu}$ cladding.

One can see in Figures 6a and 7a a strongly deformed fine-grained microstructure that formed in the $\mathrm{Cu}$ cladding. The mean sizes of the fragments were $0.2-0.5 \mu \mathrm{m}$.

According to the results of the EDS microanalysis, $\mathrm{Cu}$ and $\mathrm{Al}$ are present simultaneously in the amorphous phase at the Al-Cu interphase boundary (Figure 7). The Cu content in the Al matrix at the distances greater than 2-3 $\mu \mathrm{m}$ from the wire surface was small and didn't exceed the measurement uncertainty. 


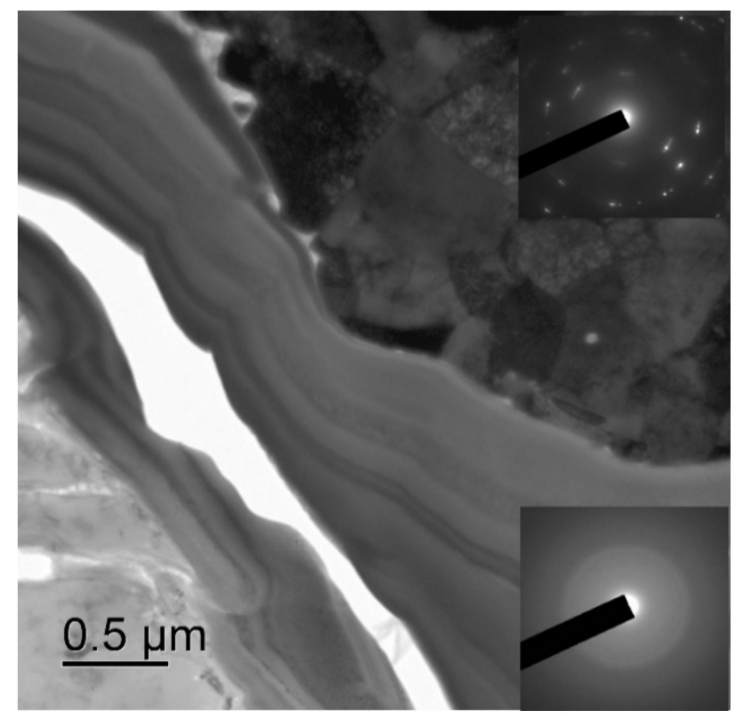

(a)

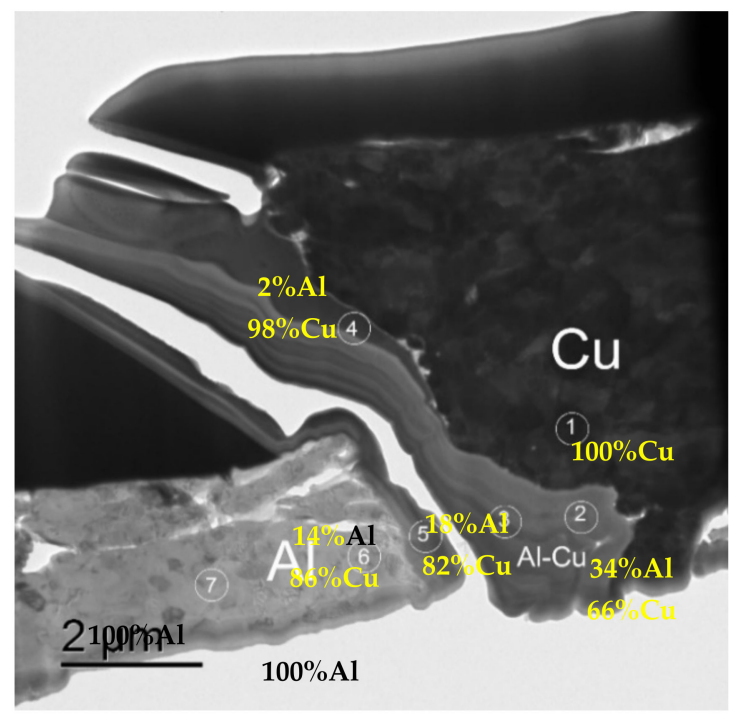

(b)

Figure 7. The results of the electron microscopy investigations of the interphase boundary in the bimetallic wire that were made from Alloy \#3: (a) general view; (b) the results of the energy dispersion spectrometer (EDS) microanalysis (in wt.\%).

The results of investigations of the mechanical properties of the $\mathrm{Al}$ wires in the initial state are presented in Table 1. Comparing the results of the microhardness investigations of the bimetallic wires (Table 1) and of the cast alloys (see Section 3.1) demonstrated the severe plastic deformation of the $\mathrm{Al}$ workpiece by rolling that resulted in an increase in the hardness by a factor of 1.5-2. The minimum microhardness was observed for the wire made from pure $\mathrm{Al}(220 \mathrm{MPa})$ whereas the maximum microhardness was $605-625 \mathrm{MPa}$ for the wires that were made from the alloys \#3 and \#6 containing $0.1 \%$ Sc. The microhardness values of the wires that were made from the Hf-containing alloys \#4 and \#5 were 540-565 MPa. These values are slightly lower than the values of the wires that were made from Alloy \#3 (625 MPa). Analysis of the data that are presented in Figure 8 shows the curves hardness $\mathrm{H}_{\mathrm{v}}$-ultimate strength $\sigma_{\mathrm{b}}$ for the non-annealed wires to have an almost linear character; the mean value of the proportionality coefficient of $\mathrm{H}_{\mathrm{v}} / \sigma_{\mathrm{b}} \sim 2$.

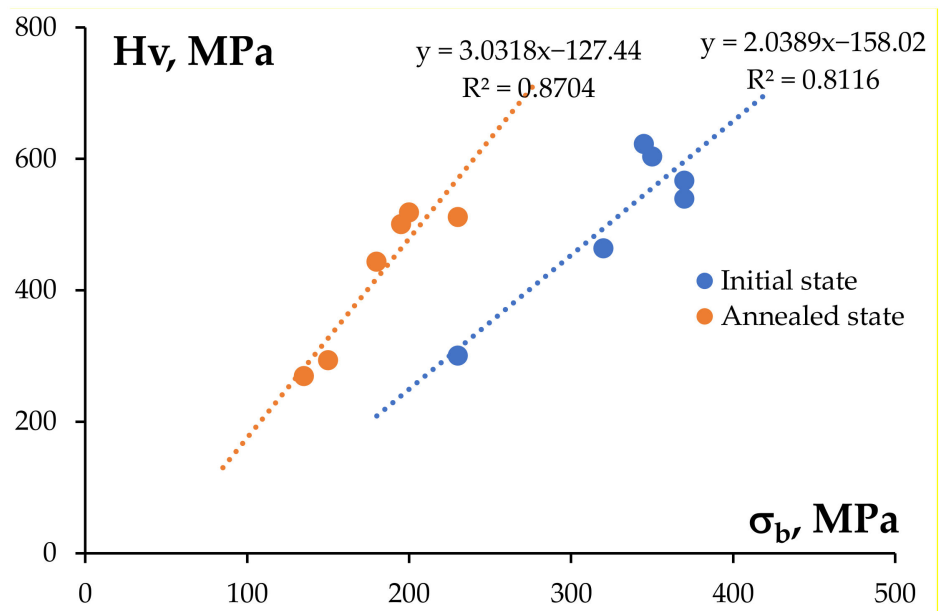

Figure 8. The dependencies $\mathrm{H}_{\mathrm{V}}\left(\sigma_{\mathrm{b}}\right)$ for the bimetallic wires in the non-annealed state and after annealing at $450{ }^{\circ} \mathrm{C}(30 \mathrm{~min})$.

The tension curves $\sigma(\varepsilon)$ for the sample wires in the initial state and after annealing at $500{ }^{\circ} \mathrm{C}(30 \mathrm{~min})$ are presented in Figure 9. The results of the mechanical tests demonstrated the bimetallic wires to have a high strength in the initial state. The maximum values of the 
ultimate strength $\left(\sigma_{\mathrm{b}}=370 \mathrm{MPa}\right)$ were observed for the wires that were made from alloys \#4-5 whereas the minimum ones were $\sigma_{\mathrm{b}}=230 \mathrm{MPa}$ for the wires that were made from pure $\mathrm{Al}$ (Alloy \#1). The ultimate strength of the wire that was made from Alloy \#3 containing $0.1 \%$ Sc was $345 \mathrm{MPa}$ and, taking into account the scatter of the properties, appeared to be close enough to the ultimate strength of the wires that were made from alloys \#4 and 5. The analysis of the tension curves $\sigma(\varepsilon)$ shows the plasticity of all the wires in the initial state to be very small: the stable plastic flow stages were almost absent and the wires were brittle and broke upon achieving the ultimate strength (Figure 9). The relative elongation to failure $(\delta)$ didn't exceed $0.5-1 \%$.

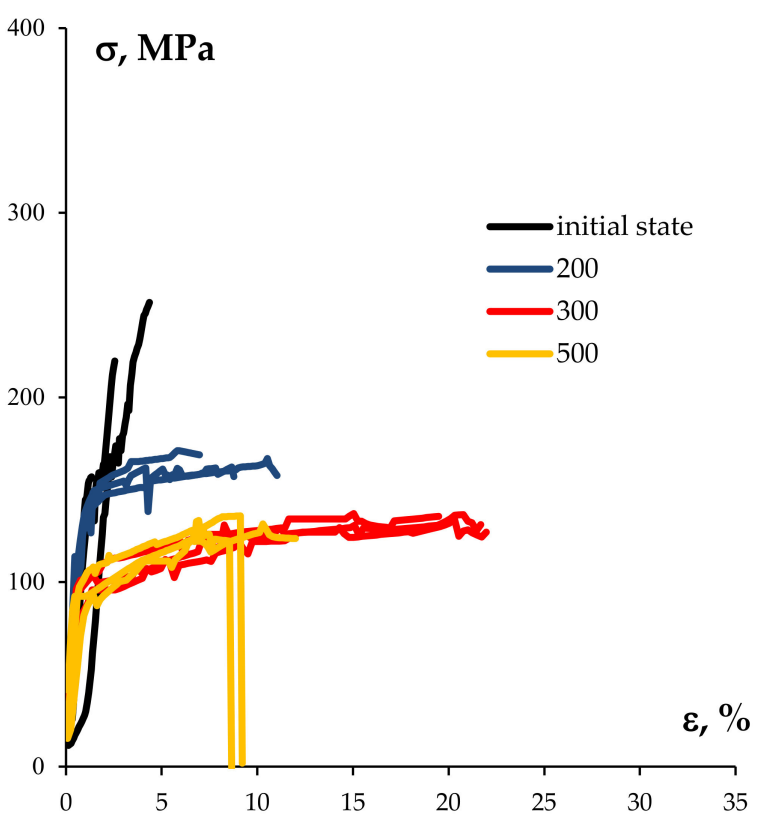

(a)

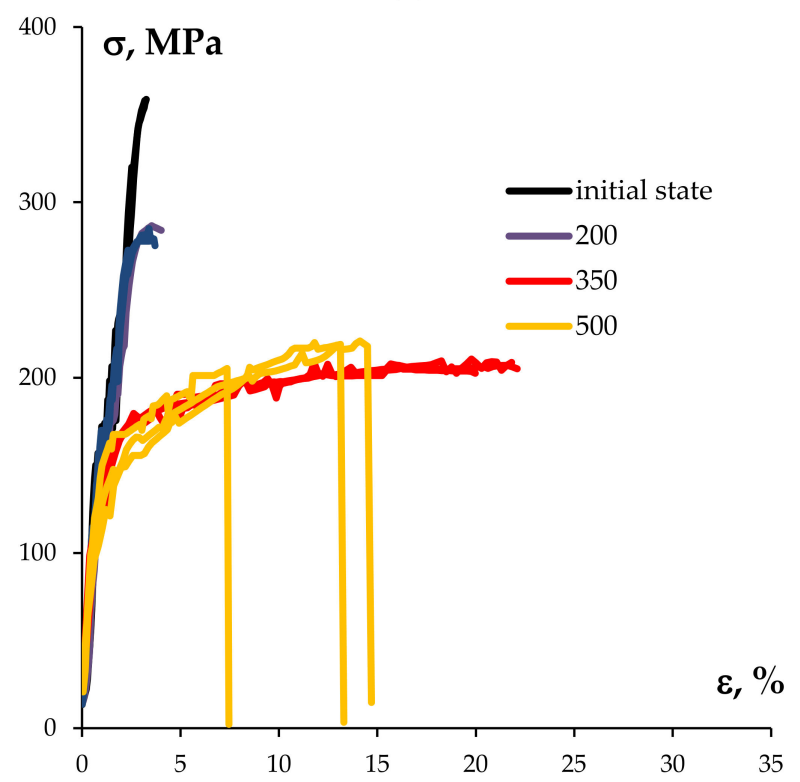

(c)

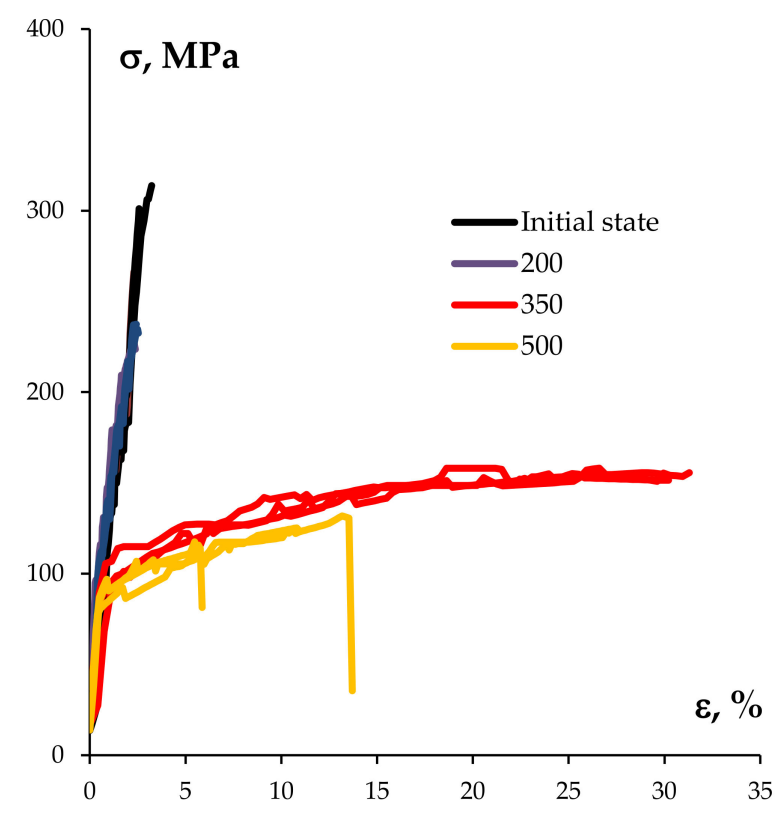

(b)

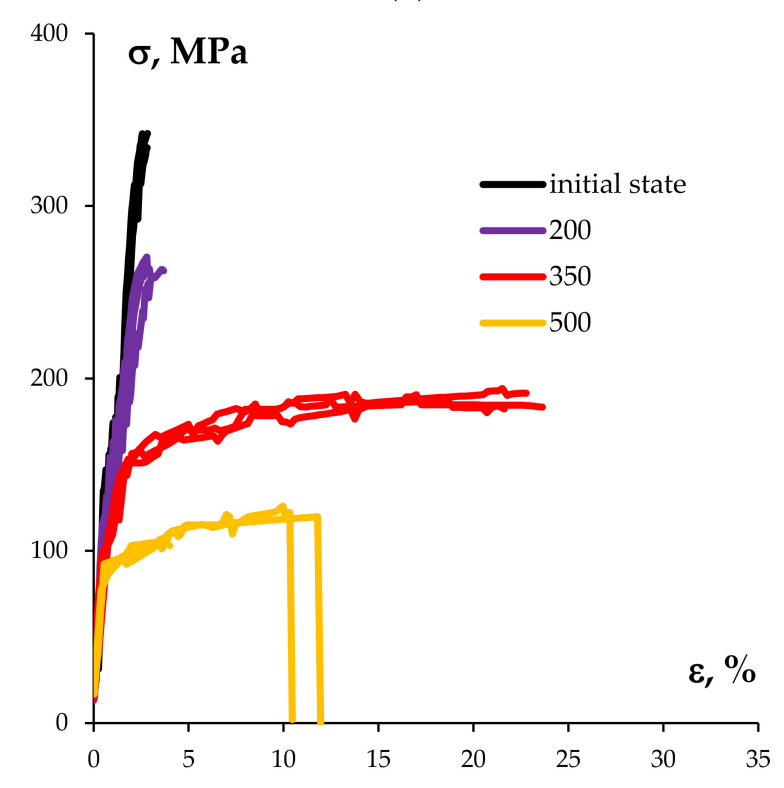

(d)

Figure 9. Cont. 


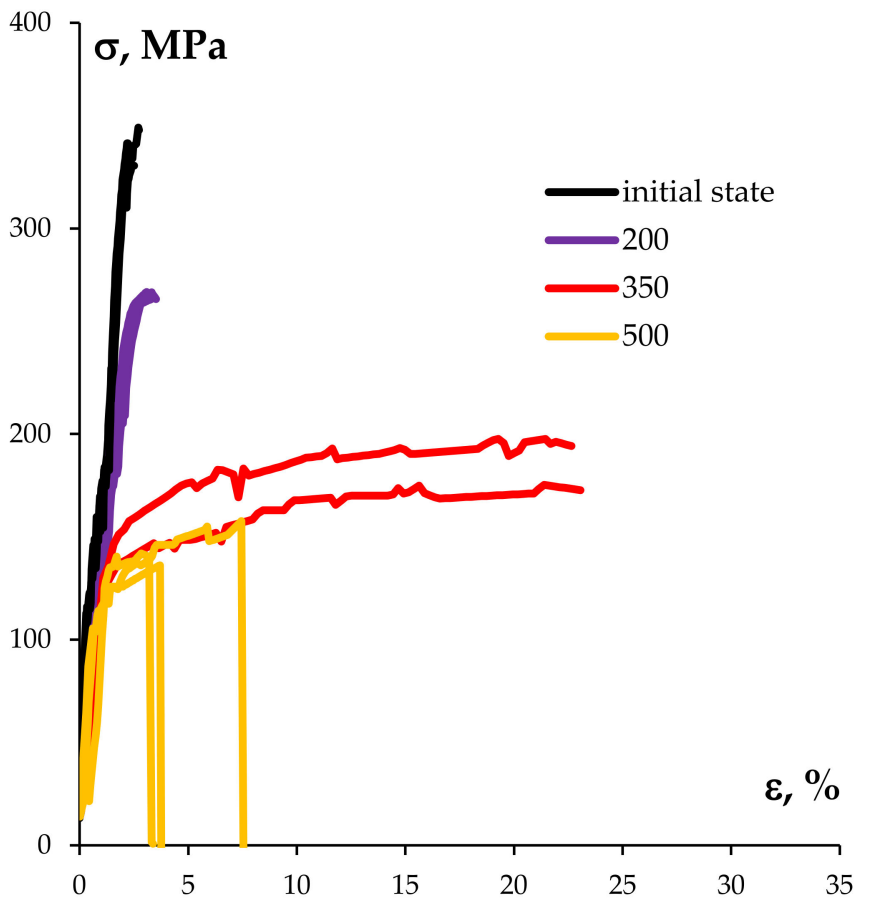

(e)

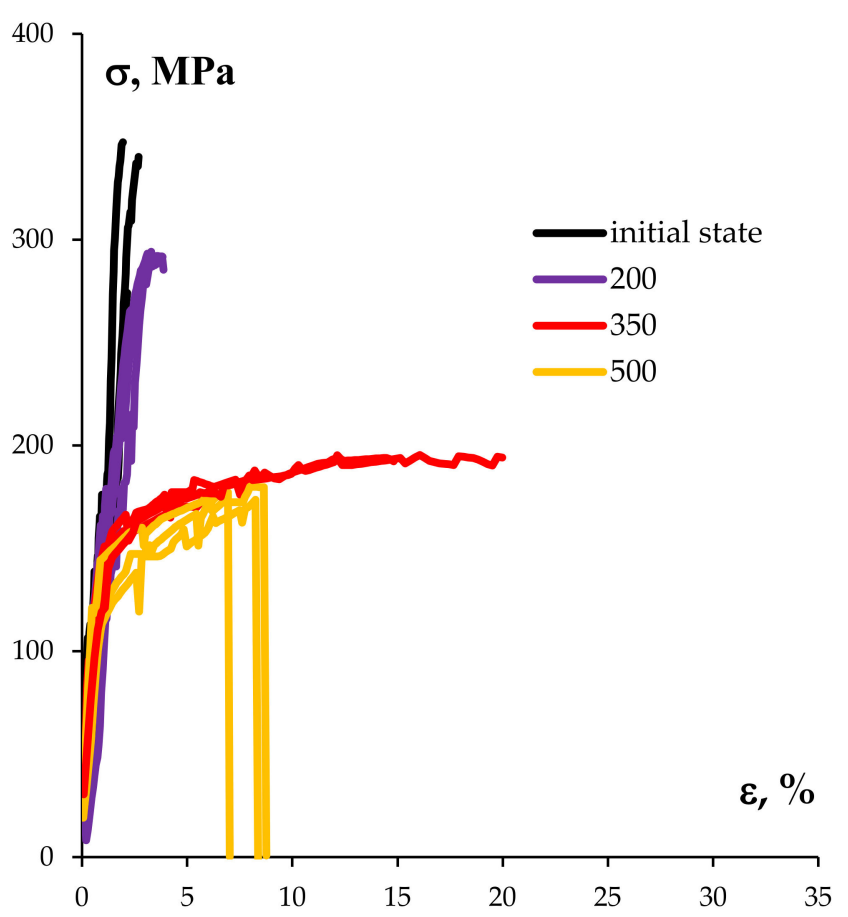

(f)

Figure 9. The tension curves $\sigma(\varepsilon)$ of the sample wires made from alloys \#1 (a), \#2 (b), \#3 (c), \#4 (d), \#5 (e), and \#6 (f).

The fractographic analysis of the destruction areas (Figure 10) shows the destruction to become brittle after cutting, which goes through a shear along the slip plane. The detachment of the $\mathrm{Cu}$ cladding from the $\mathrm{Al}$ wire was observed on the fractures that may be evidence of an insufficient level of the adhesion strength of the Al-Cu interphase boundary. The $\mathrm{Cu}$ cladding collapsed viscously in the tension tests with the formation of micropores. There were no essential differences that were observed in the fractures of sample wires that were made from different alloys.

Figure 11a shows the dependencies of the microhardness on the 30 min annealing temperature, which had a monotonously decreasing character. The microstructure measurements were performed in the central parts of the wire cross-sections. Note that despite a high microhardness of the wires that were made from Alloy \#2 (Al- $0.25 \% \mathrm{Zr}$ ) in the initial state, heating up to $200{ }^{\circ} \mathrm{C}$ and higher resulted in a rapid softening of the wires. After annealing at $450^{\circ} \mathrm{C}$, the microhardness of the wires $(295 \mathrm{MPa})$ differed from the wires that were made from pure $\mathrm{Al}(270 \mathrm{MPa})$. The analysis of the dependencies $\mathrm{H}_{\mathrm{V}}(\mathrm{T})$ demonstrated the adding of Sc and Hf to the Al- $0.25 \% \mathrm{Zr}$ alloys decreased the intensity of decreasing of hardness during annealing. The highest microhardness (500-520 MPa) after annealing was observed for alloys \#3, 5, and 6 containing from $0.05 \%$ up to $0.1 \%$ Sc. The microhardness of the annealed Alloy \#4 containing $0.1 \% \mathrm{Hf}$ ( $445 \mathrm{MPa}$ ) appeared to be slightly lower than the Sc-containing alloys \#3 and \#5 after similar annealing. The differences in the microhardness of the annealed alloys \#2-4 were insufficient and didn't exceed the scatter of properties. 


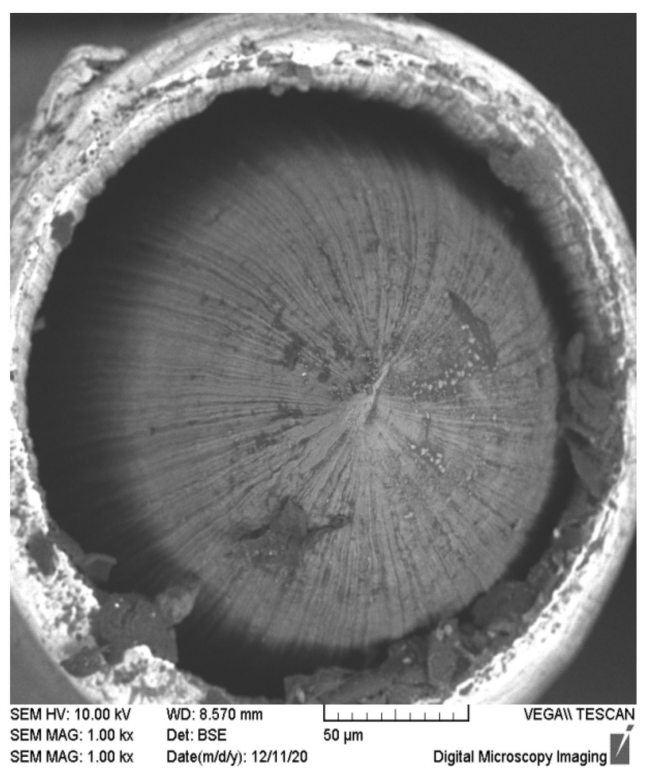

(a)

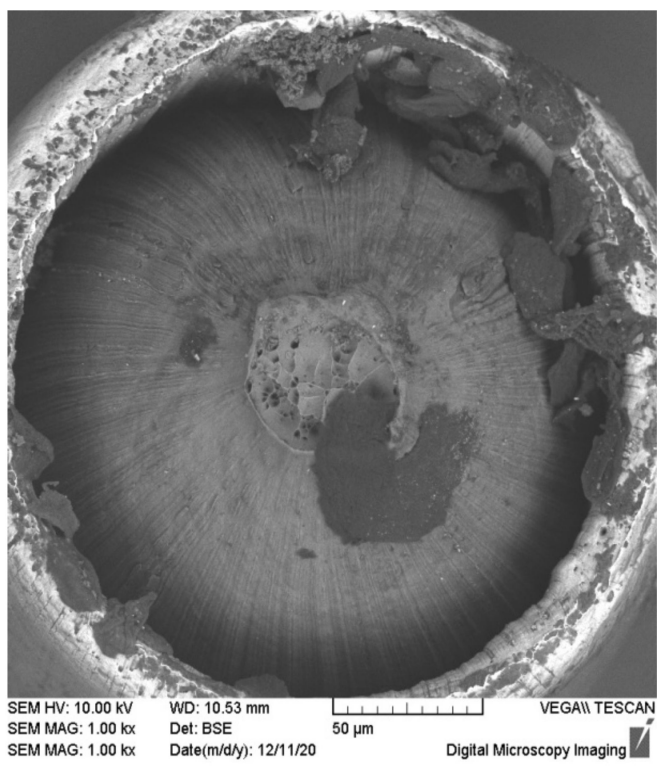

(c)

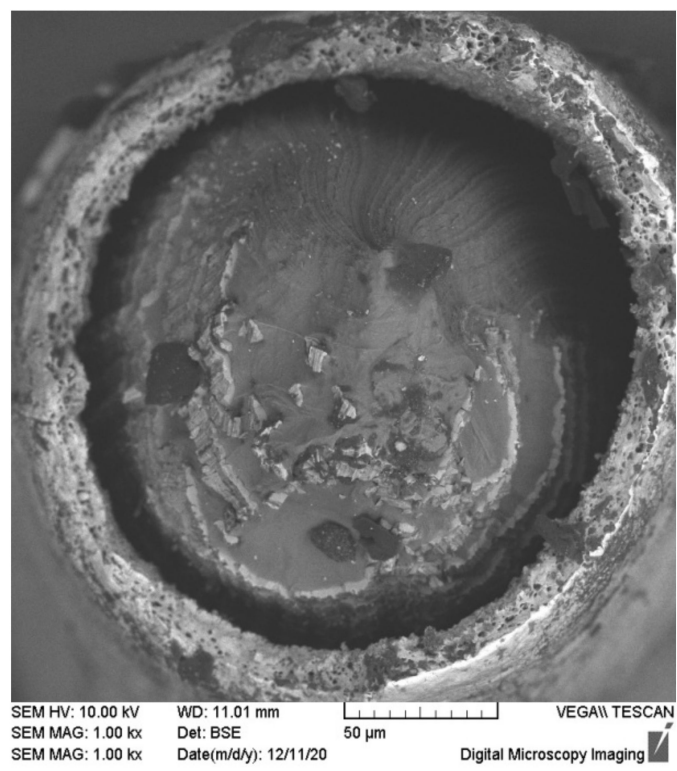

(b)

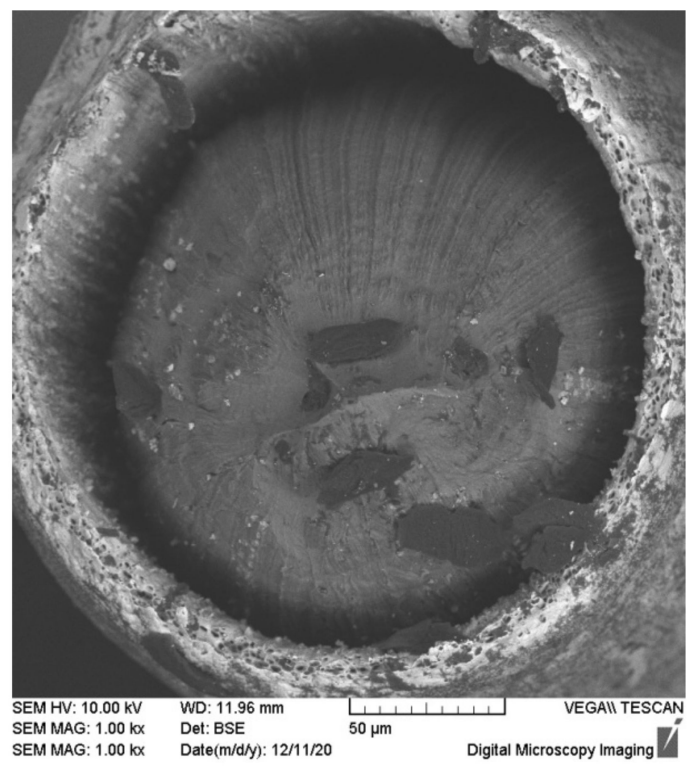

(d)

Figure 10. Fractographic analysis of the fractures of the sample bimetallic wires from Alloy \#1 (a,b) and from Alloy \#3 (c,d) after the tension tests: $(\mathbf{a}, \mathbf{c})$ without annealing; $(\mathbf{b}, \mathbf{d})$ and annealed at $500{ }^{\circ} \mathrm{C}$ for $30 \mathrm{~min}$.

The tension mechanical tests of the wires have shown the annealing to result in a reduction of the strength and in a considerable increasing of plasticity (Figure 11b,c). As one can see in Figure 9, the stage of stable plastic flow of the annealed wire metal has been observed in the $\sigma(\varepsilon)$ curves while the magnitude of the elongation to failure $(\delta)$ for the majority of the wires reached the magnitude of more than $10 \%$.

It is interesting to note that the dependencies $\delta(\mathrm{T})$ of all the wires were non-monotonous with maxima at $300{ }^{\circ} \mathrm{C}$ for the wire from Alloy $\# 1$ and $350{ }^{\circ} \mathrm{C}$ for the ones that were made from alloys \#2-6. The maximum elongation to failure $(\sim 30 \pm 2.1 \%)$ was achieved at the annealing of the wire that was made from Alloy \#2 and the minimum of $\sim 16 \pm 1.7 \%$ at the annealing of Alloy \#6. The annealing at temperatures over $350{ }^{\circ} \mathrm{C}$ resulted in a drastic reduction of the elongation to failure down to $\delta \sim 5-12 \%$. Note that the reduction of plasticity was observed for the sample wires that were made from pure Al (Alloy \#1) as 
well- $\delta \sim 9 \pm 1.2 \%$ after annealing at $500{ }^{\circ} \mathrm{C}$. The elongation of the wire from pure $\mathrm{Al}$ after annealing at $300{ }^{\circ} \mathrm{C}$ was $\sim 20 \pm 2.6 \%$.

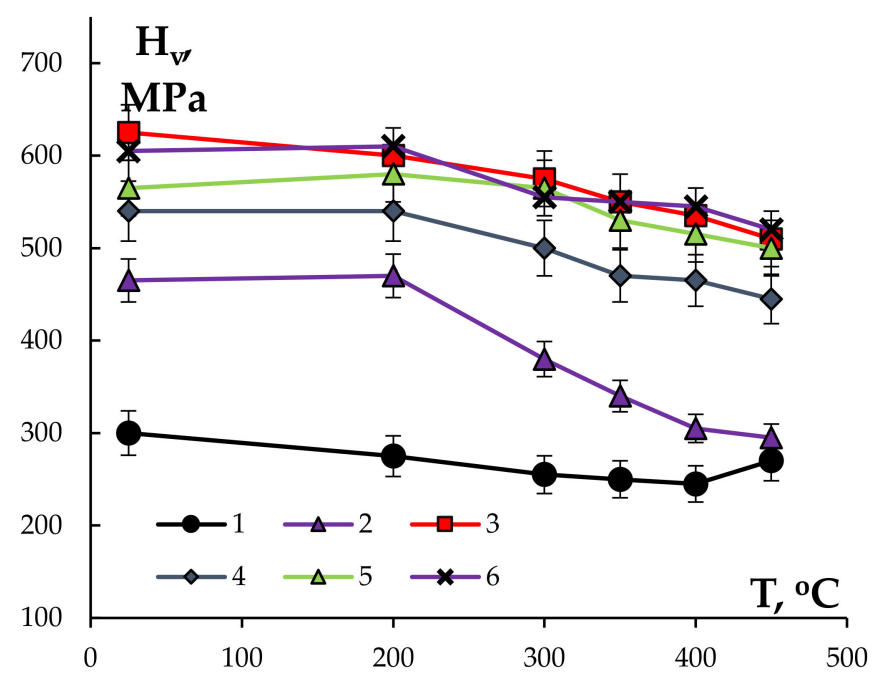

(a)

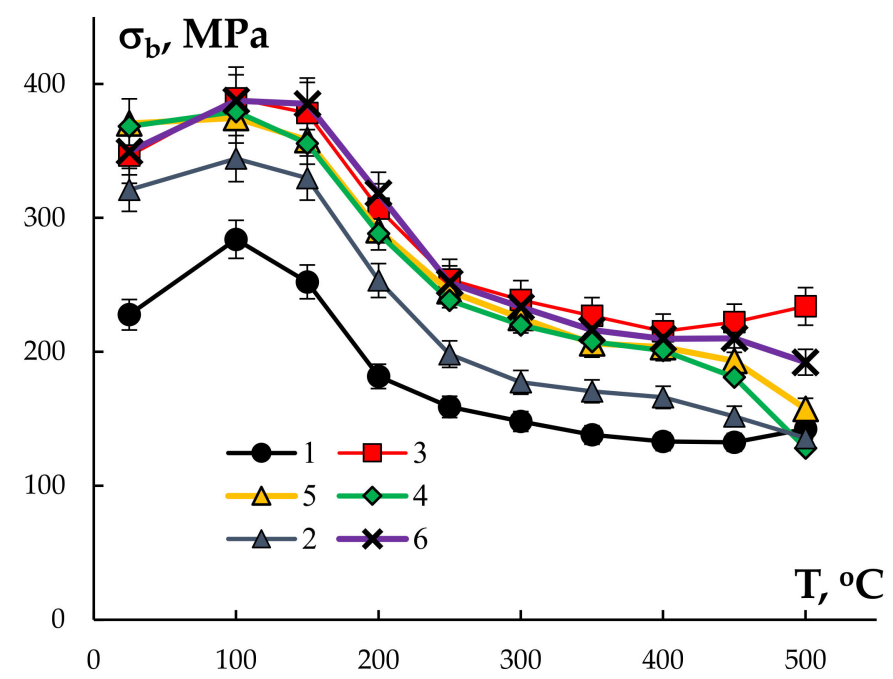

(b)

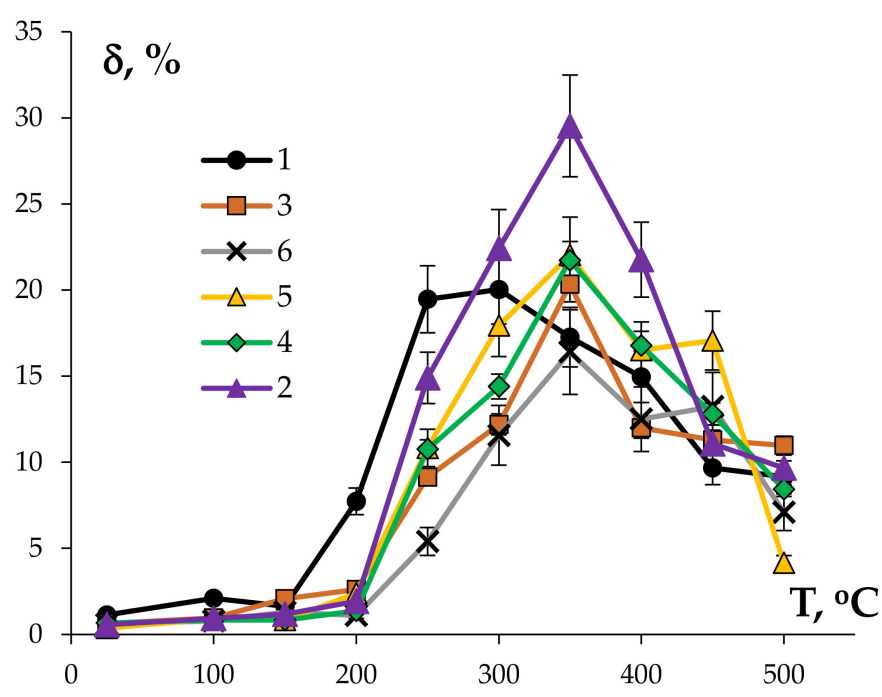

(c)

Figure 11. The dependencies of the mechanical properties on the $30 \mathrm{~min}$ annealing temperature for the sample bimetallic wires: (a) microhardness $\left(\mathrm{H}_{\mathrm{v}}\right) ;(\mathbf{b})$ ultimate strength $\left(\sigma_{\mathrm{b}}\right)$; and (c) elongation to failure $(\delta)$.

The maximum values of the ultimate strength (Figure 11b) were observed for the annealed wires that were made from alloys \#3 and \#6 containing $0.1 \%$ Sc. The magnitudes of the ultimate strength of the wires that were made from alloys \#5 (Al- $0.25 \% \mathrm{Zr}-0.05 \% \mathrm{Sc}$ $0.05 \% \mathrm{Hf}$ ) and \#4 (Al-0.25\% Zr-0.1\%Hf) after annealing at $500{ }^{\circ} \mathrm{C}$ (30 min) were $195 \mathrm{MPa}$ and $180 \mathrm{MPa}$, respectively. The magnitude of $\sigma_{\mathrm{b}}$ for the wire that was made from Alloy \#2 after annealing at $500{ }^{\circ} \mathrm{C}$ (30 min) was close to that of the annealed wire from high-purity $\mathrm{Al}$ (see Table 1). Note also that the magnitudes of the aspect ratio $\mathrm{H}_{\mathrm{V}} / \sigma_{\mathrm{b}}$ for the annealed wires were slightly higher than for the bimetallic wires in the initial state (Figure 8).

An increased plasticity of the bimetallic wires evidences that the annealing resulted in the grain growth and in the formation of a uniform fine-grained structure whereas the increased hardness and strength of the sample wires is provided by the nucleation of the $\mathrm{Al}_{3}(\mathrm{Zr}, \mathrm{Sc}, \mathrm{Hf})$ particles. Figure 12 shows the SEM images of the microstructure of an annealed bimetallic wire that was made from Alloy \#6. 


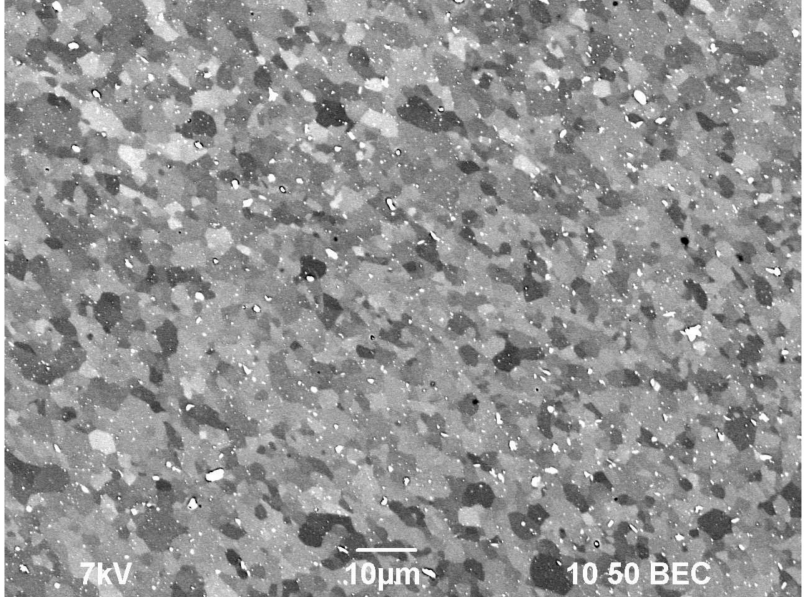

(a)

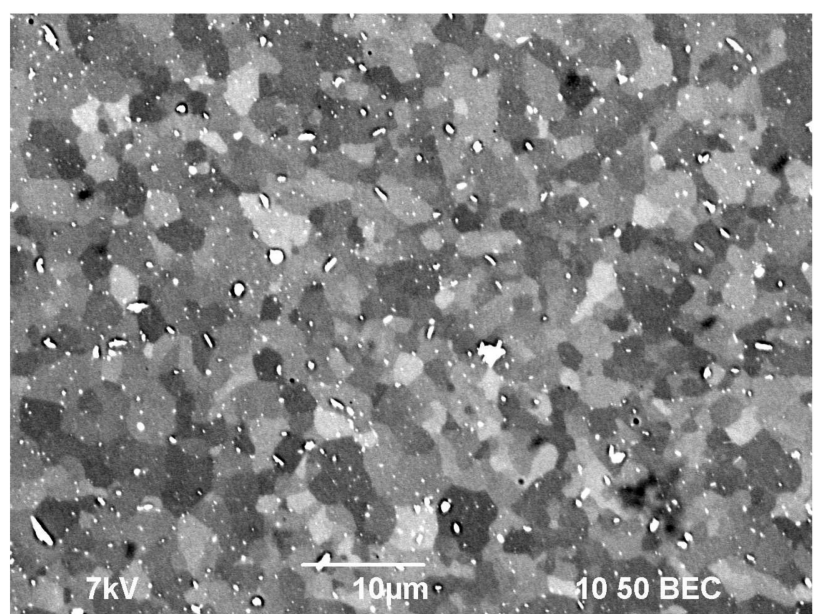

(b)

Figure 12. The microstructure of the central part of the wire that was made from Alloy \#6 after annealing at $450{ }^{\circ} \mathrm{C}$ for $30 \mathrm{~min}$. (a) small zooming; (b) large zooming.

One can see from Figure 12 that a uniform, fine-grained microstructure was formed in the wires that were made from alloys \#2-6 after the high-temperature annealing at $450{ }^{\circ} \mathrm{C}$. The mean grain sizes were 3-5 $\mu \mathrm{m}$ or less.

The fractographic analysis of the fractures has shown the annealing not to affect the character of destruction essentially, but to result in an increasing of the destruction zone and in a decreasing of the degree of the detachment of the $\mathrm{Cu}$ claddings from the $\mathrm{Al}$ wires (Figure 11c,d). This may be evidence of a diffusion of $\mathrm{Cu}$ inside the $\mathrm{Al}$ wire surfaces to occur in the course of heating. This conclusion was confirmed indirectly by the results of the metallographic investigations of the macrostructure of the wire cross-sections. As one can see in Figure 13a, brighter-looking zones of $\sim 30-40 \mu \mathrm{m}$ in width were formed at the sides of the wire cross-sections after annealing. According to the EDS microanalysis results (Figure 13b), an increased Cu concentration (2-2.4 wt.\%) was observed in these zones. The boundary of such a zone is marked by a yellow dashed line in Figure 13a. The results of the SEM investigations evidence brittle intermetallides to form at the interphase boundary of the $\mathrm{Cu}$ cladding with the Al wire after annealing (Point \#5 in Figure 13b), which are, in our opinion, the origin of the reduced adhesion strength of the Al-Cu interphase boundaries. The precipitation that formed at the interphase boundary of the $\mathrm{Cu}-\mathrm{Al}$ layers are presented in [36-38].

Figure 14 presents the dependence of SER on the annealing temperature for the bimetallic wires of different compositions. First, note that the low SER values of the wires in the initial state likely originate from the presence of thin $\mathrm{Cu}$ claddings, the conductivity of which is higher than the one of $\mathrm{Al}$ alloys. This conclusion was confirmed by the results of SER measurements of the wires from pure Al (Alloy \#1) without the Cu claddings-the measured SER values were $2.60-2.63 \mu \Omega \cdot \mathrm{cm}$. These values were close to the SER of Alloy $\# 1$ after casting as well as to the one after ECAP and annealing (see Section 3.1) within the measurement uncertainty $( \pm 0.03 \mu \Omega \cdot \mathrm{cm})$.

The SER magnitude for the bimetallic wire that was made from pure Al (Alloy \#1) almost didn't change with increasing annealing temperature up to $400{ }^{\circ} \mathrm{C}$ and was $\sim 2.4 \mu \Omega \cdot \mathrm{cm}$ (Figure 14). Further increasing the annealing temperature up to $450-500{ }^{\circ} \mathrm{C}$ resulted in a drastic increase of SER up to $\sim 2.7-2.9 \mu \Omega \cdot \mathrm{cm}$ that was probably due to an intensive diffusion of $\mathrm{Cu}$ into the $\mathrm{Al}$ wire and to the formation of a Al-Cu alloy in the subsurface layers of the wire (see Figure 13b). A similar effect was observed for the alloy Al- $0.25 \% \mathrm{Zr}$ (Alloy \#2), where the nucleation of $\mathrm{Al}_{3} \mathrm{Zr}$ particles at these temperatures (below $400{ }^{\circ} \mathrm{C}$ ) and annealing time (30 min) was very low intensive in (see $[30,33,34])$. 


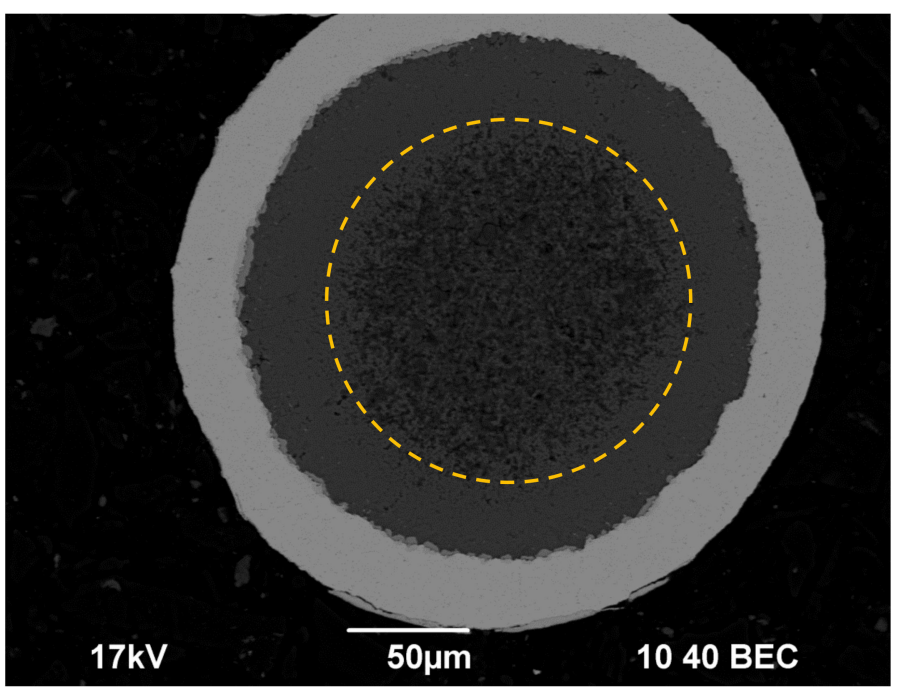

(a)

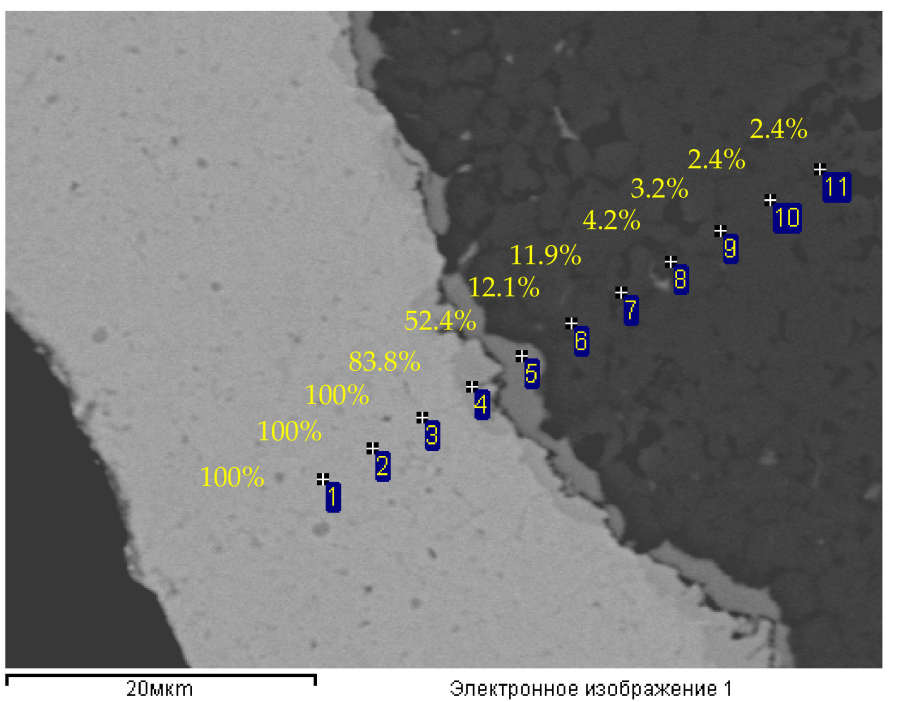

(b)

Figure 13. Macro- (a) and micro-structure (b) of a cross-section of the wire that was made from Alloy \#1 and annealed at $500{ }^{\circ} \mathrm{C}$ for $30 \mathrm{~min}$. The numbers in Figure $13 \mathrm{~b}$ denote the $\mathrm{Cu}$ concentration (in wt.\%) according to the EDS microanalysis (Al-balance).

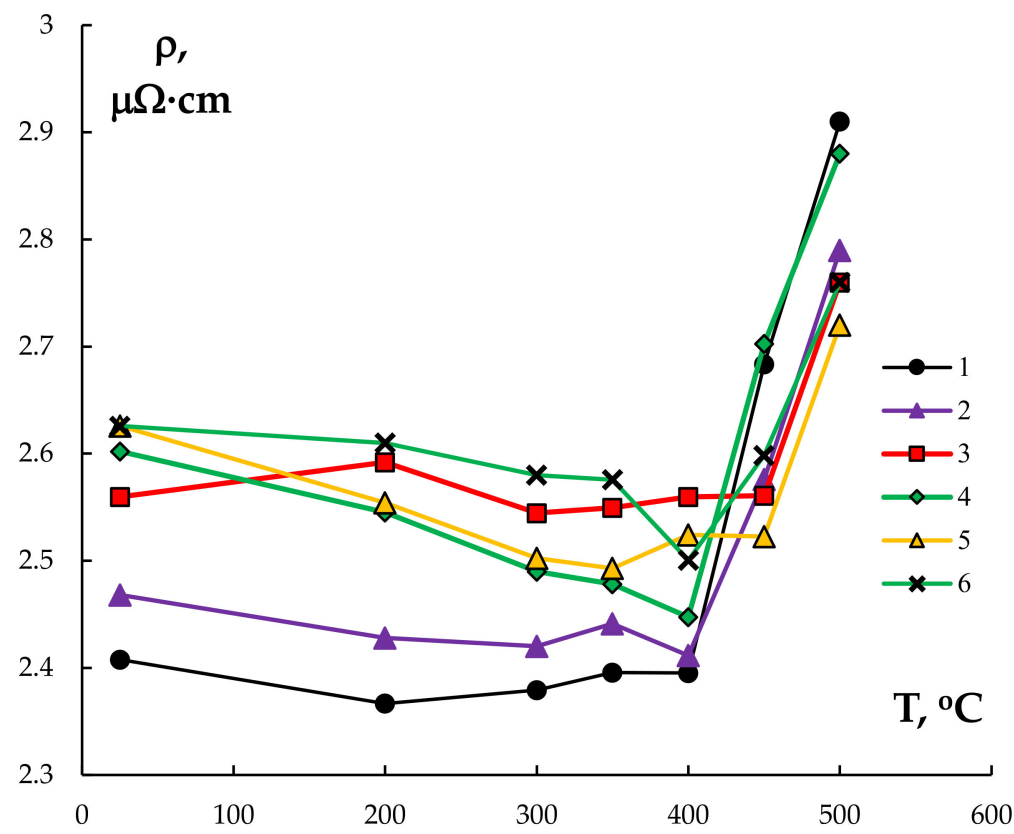

Figure 14. The dependencies of SER of the bimetallic wires on the $30 \mathrm{~min}$ annealing temperature.

Note that a reduction of the elongation to failure of the bimetallic wires was observed after annealing at $400{ }^{\circ} \mathrm{C}$ (Figure 11c). This suggests that just the diffusion of $\mathrm{Cu}$ inside the $\mathrm{Al}$ wires and the formation of large particles at the interphase boundary (Figure 13b) are the origins of the reduction of plasticity of the bimetallic wires.

One can see from Figure 14 that increasing the temperature of the $30 \mathrm{~min}$ annealing of the wires that were made from the $\mathrm{Al}-(0.2,0.25) \% \mathrm{Zr}-(\mathrm{Sc}, \mathrm{Hf})$ alloys up to $350-400{ }^{\circ} \mathrm{C}$ resulted in a monotonous decreasing of the SER. According to [39], the decreasing of SER is caused by the alloy decomposition. This conclusion was confirmed by the results of the TEM investigations. As one can see in Figure 15, there are some intermetallide nanoparticles in the annealed sample wire material. The most expressed decreasing of the SER and, hence, the most intensive nucleation of the intermetallide nanoparticles was observed for the wires that were made from alloys \#4 and \#5. 


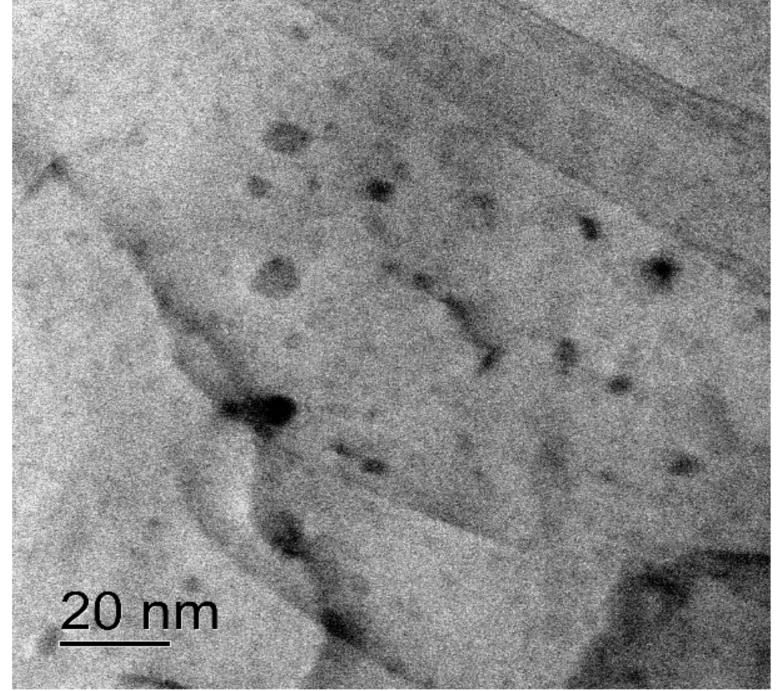

(a)

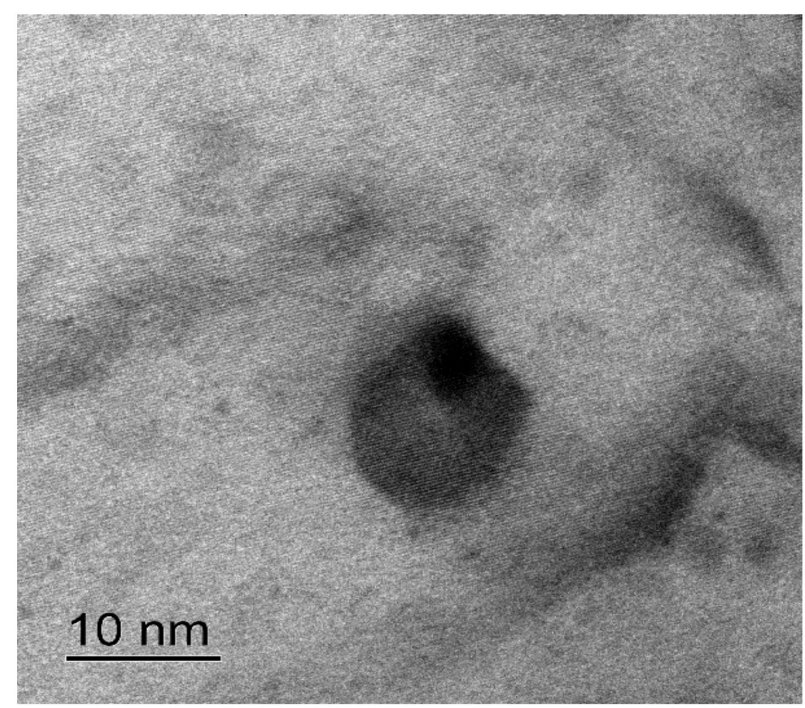

(b)

Figure 15. Nucleation of the $\mathrm{Al}_{3} \mathrm{Zr}$ intermetallide nanoparticles in the annealed wire made from Alloy \#2. TEM. (a) small zooming; (b) large zooming.

\section{Discussion}

\subsection{Effect of Annealing on the Microstrucutre Stability of the Al Alloys}

As it has been mentioned above in Materials and Methods section, the nucleation of the $\mathrm{Al}_{3} \mathrm{X}$ intermetallide nanoparticles ensuring high thermal stability of the fine-grained microstructure of the bimetallic wires was one of the purposes of the preliminary annealing of the deformed workpieces at $300-400{ }^{\circ} \mathrm{C}$.

According to [40], the scale of decreasing of the alloy SER $(\Delta \rho)$ in the course of annealing is proportional to the degree of the decomposition of solid solution $\Delta \mathrm{C}$ and to the volume fraction of the nucleated particles $\mathrm{f}_{\mathrm{v}}$. Here $\Delta \mathrm{C}$ is the variation of the doping element concentrations in the solid solution during annealing. It follows from the data that are presented in Section 3.1 that the magnitudes of $\Delta \mathrm{C}$ after annealing at $400{ }^{\circ} \mathrm{C}(2 \mathrm{~h})$ were $0.51,0.51$, and $0.41 \mu \Omega \cdot \mathrm{cm}$ for alloys \#3, 4, and 5, respectively. Taking the SER of pure $\mathrm{Al}$ (Alloy \#1) to be $\rho_{\mathrm{Al}}=2.65-2.66 \mu \Omega \cdot \mathrm{cm}$ (see Section 3.1), one can estimate the alloy magnitude $\Delta C$ according to the formula: $\Delta C_{i}=100 \% \cdot\left[\Delta \rho / \Delta \rho_{\max }\right]$ where $\Delta \rho_{\max }=\rho_{I}-\rho_{A l}$ and $\rho_{i}$ is the SER of the $i^{\text {th }}$ alloy. For alloys of $i=3,4$, and 5 , one obtains $\Delta C_{i}$ to be 65,63 , and $58 \%$, respectively (Table 3 ). So far, the maximum alloy decomposition solid solution degree $\left(\Delta \mathrm{C}_{3} \sim 65 \%\right)$ after annealing at $400{ }^{\circ} \mathrm{C}$ was observed for Alloy \#3 (Al-0.25\%Zr-0.1\%Sc). Also, the minimum mean grain size $(\sim 150 \mu \mathrm{m})$ after annealing was observed in this alloy. Note that a complete substitution of $0.1 \%$ Sc (Alloy \#3) for $0.1 \% \mathrm{Hf}$ (Alloy \#4) appeared to be very efficient; the mean grain size in Alloy \#4 was $\sim 200 \mu \mathrm{m}$ (that was close to the mean grain size in annealed Alloy \#4) at comparable alloy decomposition solid solution degree $\left(\Delta \mathrm{C}_{5} \sim 58 \%\right)$. The maximum volume fractions of the second phase particles $\mathrm{f}_{\mathrm{v}}{ }^{\max }$ in the investigated $\mathrm{Al}$ alloys were calculated according to procedure that was described in [41]. The volume fractions of the particles that were nucleated in the course of annealing were calculated according to the formula: $f_{v}=f_{v}{ }^{m a x} \cdot \Delta C_{i}$. The values of $f_{v}{ }^{\max }$ and $f_{v}$ for each alloy are presented in Table 3.

The partial substitution of Sc for Hf (alloys \#5 and 6) was not efficient. The mean grain sizes in the annealed alloys \#5 and 6 were $1 \mathrm{~mm}$ at high enough alloy decomposition solid solution degree $(\Delta \mathrm{C} \sim 61-63 \%)$ and a considerable volume fraction of the nucleated particles $\left(f_{\mathrm{v}} \sim 0.27-0.34 \%\right)$. The origin of this is not clear enough yet. 
Table 3. Analysis of the parameters of the particles that were nucleating in the investigated alloys.

\begin{tabular}{|c|c|c|c|c|c|c|c|c|c|c|}
\hline \multirow{3}{*}{ Alloy } & \multicolumn{7}{|c|}{ Alloying Elements Concentration } & \multirow{3}{*}{$\mathrm{f}_{\mathrm{v}}^{\max }, \%$} & \multirow{3}{*}{$\Delta \mathrm{C}_{\mathrm{i}}, \%$} & \multirow{3}{*}{$\mathbf{f}_{\mathrm{v}}, \%$} \\
\hline & \multicolumn{2}{|c|}{$\mathrm{Zr}$} & \multicolumn{2}{|c|}{ Sc } & \multicolumn{2}{|c|}{ Hf } & \multirow{2}{*}{$\mathrm{Zr}+\mathrm{Sc}+\mathrm{Hf}$, at. $\%$} & & & \\
\hline & wt.\% & at. $\%$ & wt. $\%$ & at. $\%$ & wt. $\%$ & at. $\%$ & & & & \\
\hline \#2 & 0.25 & 0.073 & - & - & - & - & 0.073 & 0.30 & 18 & 0.05 \\
\hline \#3 & 0.25 & 0.073 & 0.10 & 0.06 & - & - & 0.133 & 0.54 & 65 & 0.35 \\
\hline$\# 4$ & 0.25 & 0.073 & - & - & 0.10 & 0.015 & 0.088 & 0.36 & 58 & 0.21 \\
\hline \#5 & 0.25 & 0.073 & 0.05 & 0.03 & 0.05 & 0.008 & 0.111 & 0.45 & 61 & 0.27 \\
\hline \#6 & 0.20 & 0.059 & 0.10 & 0.06 & 0.10 & 0.015 & 0.134 & 0.54 & 63 & 0.34 \\
\hline
\end{tabular}

We suggest this to be related to a separate nucleation of the $\mathrm{Al}_{3}(\mathrm{Zr}, \mathrm{Sc})$ and $\mathrm{Al}_{3}(\mathrm{Sc}, \mathrm{Hf})$ particles in the multicomponent $\mathrm{Al}$ alloys \#5 and 6 containing Sc, Zr, and $\mathrm{Hf}$ simultaneously.

This suggestion is supported indirectly by the fact that the mean grain sizes in the alloys of the Al-Zr-Sc-Hf system (alloys \#5 and 6) after annealing at $400{ }^{\circ} \mathrm{C}$ for $2 \mathrm{~h}$ appeared larger essentially than the ones in the alloys of the Al- $0.25 \% \mathrm{Zr}-0.1 \% \mathrm{Sc}$ composition $(\sim 150-200 \mu \mathrm{m})$ and in the Al-0.25\%Zr-0.1\%Hf one ( 200 $\mu \mathrm{m})$. In our opinion, this means that the additional alloying of the Sc-containing $\mathrm{Al}$ alloys by $\mathrm{Hf}$ leads to formation of the incoherent $\mathrm{Al}_{3}(\mathrm{Sc}, \mathrm{Hf})$ particles during annealing (see [42,43]). The fast growth of the $\mathrm{Al}_{3}(\mathrm{Sc}, \mathrm{Hf})$ non-coherent particles will lead to an intensive grain boundary migration and, as a consequence, to the formation of more coarse-grained microstructure in the course of annealing that was observed in the experiment. So far, the stabilization of the nonequilibrium microstructure in Alloy \#5 takes place preferentially by the nucleation of coherent $\mathrm{Al}_{3}(\mathrm{Sc}, \mathrm{Zr})$ nanoparticles, the volume fraction of which in Alloy \#5 will be lower than the one in Alloy \#3.

Also, it is interesting to note that wires \#5 and 6 containing Sc, Zr, and Hf together manifested a lower elongation to failure after annealing than the wires from $\mathrm{Al}-0.25 \% \mathrm{Zr}$ (Alloy \#2), Al- $0.25 \% \mathrm{Zr}-0.10 \% \mathrm{Sc}$ (Alloy \#3), or Al-0.25\%Zr-0.1\%Hf (Alloy \#4). This may indirectly prove that the non-coherent particles nucleating in alloys \#5 and 6 have an increased energy of the " $\mathrm{Al}$ matrix- $\mathrm{L}_{2}$ particle" interphase boundary or a higher shear modulus. These factors may impede "cutting" of the nucleated nanoparticles by lattice dislocations that lead to the formation of the disclination-type loops at the particles and to enhancement of the long-range internal strain fields (see [44]).

The mean grain sizes in the annealed $\mathrm{Al}-0.25 \% \mathrm{Zr}-0.1 \% \mathrm{Sc}$ alloy appeared to be $200 / 150 \sim 1.3$ times smaller than the one in the Al- $0.25 \% \mathrm{Zr}-0.1 \% \mathrm{Hf}$ alloy after similar annealing (see Section 3.1). The ratio of the volume fractions of the nucleated particles in these alloys was $\mathrm{f}_{\mathrm{v} 2} / \mathrm{f}_{\mathrm{v} 5}=0.35 / 0.21 \sim 1.5$ (see Table 3). The result that was obtained means that the insufficient increasing of the mean grain sizes observed in Alloy \#4 as compared to Alloy \#3 agrees with the decreasing of the volume fraction $f_{v}$ according to Zener ratio: $d_{Z}=k \cdot R / f_{v}$ [45]. Here, $k$ is a numerical factor depending on the particle geometry and on the interphase boundary energy and $\mathrm{R}$ is the mean size of the nucleated particles [45]. Note also that the volume fraction of the nucleated particles in the Al- $0.25 \% \mathrm{Zr}-0.1 \% \mathrm{Sc}$ alloy appeared to be greater than the one in the $\mathrm{Al}-0.25 \% \mathrm{Zr}-0.1 \% \mathrm{Hf}$ alloy after similar annealing. It means that the formation of the $\mathrm{Al}_{3}(\mathrm{Zr}, \mathrm{Hf})$ particles goes slower than the $\mathrm{Al}_{3}(\mathrm{Zr}, \mathrm{Sc})$ ones but faster than the $\mathrm{Al}_{3} \mathrm{Zr}$ particles in Alloy \#2 (Table 2).

Also, it is important to take into account that the Hf content (\%) in Alloy \#4 appeared to be lower than the Sc one (\%) in Alloy \#3 (Table 2). So far, the replacement of $0.1 \mathrm{wt} . \%$ Sc by $0.1 \mathrm{wt} . \% \mathrm{Hf}$ will lead to a reduction of the maximum volume fraction of the $\mathrm{Al}_{3} \mathrm{X}$ particles, which may nucleate in the alloy at the same annealing conditions.

\subsection{Effect of Annealing on the Stability of the Mechanical Properties of the Wires}

The presence of the $\mathrm{Cu}$ claddings may affect the deformation behavior of the $\mathrm{Al}$ wires. First, it is related to the contributions of the deformation and destruction of the $\mathrm{Cu}$ claddings as well as of the destruction of the interphase boundary of the $\mathrm{Cu}$ cladding with 
the $\mathrm{Al}$ wire into the deformation behavior of the wires during the tension tests. Second, the intensive diffusion of $\mathrm{Cu}$ into the $\mathrm{Al}$ alloy may affect the tension test results indirectly.

In our opinion, the intensive $\mathrm{Cu}$ diffusion into the $\mathrm{Al}$ wire surfaces is one of the origins of nonmonotonous dependence $\delta(\mathrm{T})$ (see Figure 13b). The increase of the plasticity at the annealing temperatures $<350{ }^{\circ} \mathrm{C}$ is a consequence of the recovery and recrystallization that leads to a decrease of the internal long-range stresses. The annealing at the temperatures over $350-400{ }^{\circ} \mathrm{C}$ leads to an intensive $\mathrm{Cu}$ diffusion into the $\mathrm{Al}$ wire surfaces and to the formation of large brittle Al-Cu intermetallides at the interphase boundaries between $\mathrm{Cu}$ and $\mathrm{Al}$ (Figure 13b). In our opinion, these processes lead to reduction of the relative elongation to failure of the bimetallic wires. The nucleation of the $\mathrm{Al}_{3}\left(\mathrm{Zr}_{,} \mathrm{X}\right)$ particles is an additional factor reducing the plasticity of the wires at elevated annealing temperatures. The formation of the $\mathrm{Al}_{3}(\mathrm{Zr}, \mathrm{X})$ blocks the dislocation slip in the crystal lattice and leads to the reduction of the plasticity of the Al wires.

One should pay special attention to the abnormally high intensity of diffusion of $\mathrm{Cu}$ into the $\mathrm{Al}$ wire surfaces. According to [46], the activation energy of $\mathrm{Cu}$ diffusion in $\mathrm{Al}$ crystal lattice $\left(\mathrm{Q}_{\mathrm{v}}\right)$ scatters from 15.6 to $16.9 \mathrm{kT}_{\mathrm{m}}$ whereas the pre-exponential factor is close to $\mathrm{D}_{\mathrm{v} 0} \sim 10^{-6} \mathrm{~m}^{2} / \mathrm{s}$. Here $\mathrm{T}_{\mathrm{m}}$ is the Al melting point and $\mathrm{k}$ is Boltzmann constant. Using the ordinary rule to calculate the diffusion mass transfer time $\tau_{\text {diff }}=x^{2} / D_{v}$, one can show that at $\tau_{\text {diff }}=30 \mathrm{~min}, \mathrm{D}_{\mathrm{v}}=\mathrm{D}_{\mathrm{v} 0} \exp \left(-\mathrm{Q}_{\mathrm{v}} / \mathrm{kT}\right)$, and $\mathrm{T}=450-500{ }^{\circ} \mathrm{C}(723-773 \mathrm{~K})$ means that the expected characteristic scale of $\mathrm{Cu}$ diffusion in $\mathrm{Al}$ is $\mathrm{x} \sim 4-6 \mu \mathrm{m}$. This value is much less than the scale of the $\mathrm{Cu}$ diffusion into the $\mathrm{Al}$ wire surface that was observed experimentally ( 30-40 $\mu \mathrm{m}$, see Figure 13). In our opinion, the formation of the uniform fine-grained structure in the $\mathrm{Al}$ alloy in the course of rolling is one of main origins of deep penetration of $\mathrm{Cu}$. It leads to preferential diffusion mass transfer along the grain boundaries, the diffusion permeability of which are known to exceed the one of the metal crystal lattice [47]. Since the intensity of grain boundary migration in alloys with different compositions will be different, one can expect the surface layers of the $\mathrm{Al}$ alloys to contain different $\mathrm{Cu}$ concentrations. According to the model of effect of small additives of the alloying elements on the diffusion permeability of the grain boundaries [48] and on the recrystallization temperature [49], it will also lead to change of the grain boundaries migration intensity in the surface layers of the $\mathrm{Al}$ wires. Different degrees of saturation with $\mathrm{Cu}$ for the surface layers of the wires that were made from different alloys is probably one of the origins of the observed different scales of the SER increase at the increased temperatures of annealing of the wires that were made from alloys with different compositions (Figure 14).

In this connection, to simplify the analysis of the results that were obtained, let us consider the effect of annealing on the microhardness of the central parts of the Al wires. In Figure $13 \mathrm{a}$, this area is marked by the yellow dashed line.

Figure 16 presents the dependence of the microhardness on the volume fraction of the $\mathrm{Al}_{3} \mathrm{X}$ particles in the $\mathrm{Al}$ wires in the initial state and after annealing at $400-450{ }^{\circ} \mathrm{C}$ for $30 \mathrm{~min}$. The volume fractions of the nucleated particles for the wires in the initial state were taken to be equal to the values of $f_{v}$ in the same annealed $\mathrm{Al}$ alloys, which these wires have been fabricated from (Table 3 ). The value of $f_{v}$ for each annealed wire was calculated as a sum of the volume fraction of the particles that were nucleated in the non-annealed wire and of the particles that were nucleated when annealing the bimetallic wire $\Delta \mathrm{f}_{\mathrm{v}}$. The magnitude of $\Delta \mathrm{f}_{\mathrm{v}}$ has been accepted to be proportional to the magnitude of decreasing of the SER as a result of the annealing of the wire $\left(\Delta \rho_{2}\right)$ when heating this one up to $400{ }^{\circ} \mathrm{C}$ (see Figure 14, for the description of the procedure of calculation of the volume fraction-see Section 4.1). 


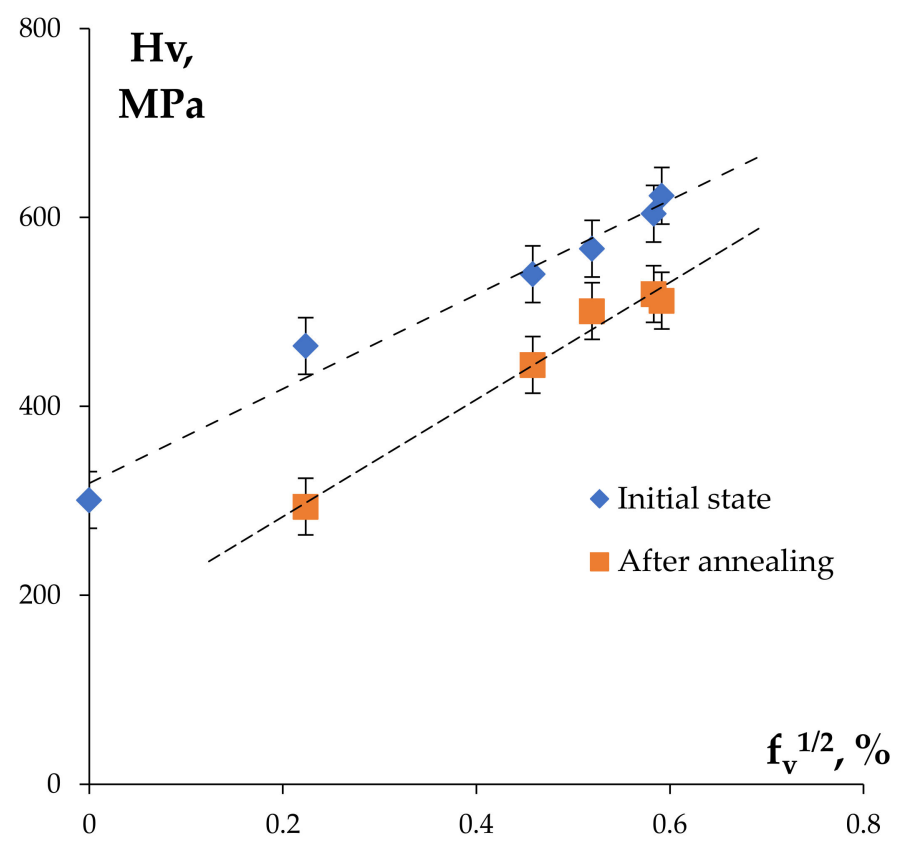

Figure 16. Dependencies of the microhardness of the $\mathrm{Al}$ wires $\mathrm{H}_{\mathrm{V}}$ on the volume fraction of the nucleated particles $f_{V}$.

Analysis of the results that were obtained showed that the curve $\mathrm{H}_{\mathrm{v}}\left(\mathrm{f}_{\mathrm{v}}\right)$ that was plotted in the $\mathrm{H}_{\mathrm{V}}-\sqrt{\mathrm{f}_{\mathrm{v}}}$ axes can be interpolated by a straight line with a good precision. This means that the dependence of the hardness of the central parts of the $\mathrm{Al}$ wires on the volume fraction of the second phase particles $\mathrm{Al}_{3} \mathrm{X}$ in the temperature interval up to $400{ }^{\circ} \mathrm{C}$ can be described using the Orowan equation: $H_{v}=\alpha G b \sqrt{f_{v}} / R$ where $\alpha$ is a numerical parameter, $\mathrm{G}$ is the shear modulus, and $\mathrm{b}$ is the Burgers vector [45].

\section{Conclusions}

The features of changes of the mechanical properties of the bimetallic microdoped $\mathrm{Al}$ wires with small cross-sections $(\varnothing 0.26 \mathrm{~mm})$ with high-purity $\mathrm{Cu}$ coatings upon annealing have been investigated.

Preliminary annealing of the $\mathrm{Al}$ alloys providing the nucleating of the second phase particles $\mathrm{Al}_{3}(\mathrm{Zr}, \mathrm{Sc}, \mathrm{Hf})$ prior to making the wires has been shown to allow the preservation of the uniform fine-grained structure with the mean grain sizes of 3-5 $\mu \mathrm{m}$ as well as with an increased strength and hardness.

The samples that were made from the $\mathrm{Al}-0.25 \% \mathrm{Zr}-(\mathrm{Sc}, \mathrm{Hf})$ alloys were found to have the highest thermal stability. The wires made from the Al-0.25\% Zr-(Sc,Hf) alloys had the highest hardness and ultimate strength after annealing. The character of fractures of the sample bimetallic composite wires in the tension tests was found to change upon annealing that was related to by the interdiffusion of $\mathrm{Cu}$ into the wire surfaces and of $\mathrm{Al}$ into the $\mathrm{Cu}$ cladding.

Author Contributions: Conceptualization, A.N. and V.C.; methodology, A.N.; formal analysis, A.N. and E.S.; investigation, I.S., V.K., A.B., N.B., A.M., N.T. and M.F.; data curation, A.N., V.C. and I.S.; writing—original draft preparation, A.N. and I.S.; writing—review and editing, V.C. and A.N.; supervision, V.C.; project administration, A.N.; funding acquisition, A.N. All authors have read and agreed to the published version of the manuscript.

Funding: The work was supported by Russian Science Foundation (grant No. 20-19-00672). The TEM study of the microstructure was carried out on the equipment of the Center Collective Use "Materials Science and Metallurgy" at National University of Science and Technology "MISIS" supported by Ministry of Science and Higher Education of Russian Federation (grant No. 075-15-2021-696).

Institutional Review Board Statement: Not applicable. 


\section{Informed Consent Statement: Not applicable.}

Data Availability Statement: Data is contained within the article.

Acknowledgments: Authors thank V. V. Zakharov (VILS, Moscow, Russia) for recommendations on the choice of the compositions of the $\mathrm{Al}$ alloys and of the casting regimes. Authors thank V. N Chepelenko (Moscow Plant for Processing Special Alloys, Russia) for making the bimetallic wires.

Conflicts of Interest: The authors declare no conflict of interest.

\section{References}

1. Medvedev, A.; Arutyunyan, A.; Lomakin, I.; Bondarenko, A.; Kazykhanov, V.; Enikeev, N.; Raab, G.; Murashkin, M. Fatigue properties of ulta-fine grained Al-Mg-Si wires with enhanced mechanical strength and electrical conductivity. Metals 2018, 8, 1034. [CrossRef]

2. Yang, C.; Masquellier, N.; Gandiolle, C.; Sauvage, X. Multifunctional properties of composition graded Al wires. Scr. Mater. 2020, 189, 21-24. [CrossRef]

3. Moisy, F.; Gueydan, A.; Sauvage, X.; Keller, C.; Guillet, A.; Nguyen, N.; Martinez, M.; Hug, E. Elaboration of architectured copper clad aluminum composites by a multi-step drawing process. Mater. Sci. Forum 2018, 941, 1914-1919. [CrossRef]

4. Matveev, Y.A.; Gavrilova, V.P.; Baranov, V.V. Light conducting materials for aircraft wires. Cables Wires 2006, 5, 22-23. (In Russian)

5. Teleshov, V.V.; Zakharov, V.V.; Zapolskaya, V.V. Development of aluminium alloys for high-temperature wires with enhanced strength and high specific electrical conduction. Light Alloy. Technol. 2018, 1, 15-26. (In Russian)

6. Belov, N.A.; Alabin, A.N.; Teleuova, A.R. Comparative analysis of alloying additives as applied to the production of heat-resistant aluminum-base wires. Met. Sci. Heat Treat. 2012, 53, 455-459. [CrossRef]

7. Korotkova, N.O.; Belov, N.A.; Timofeef, V.N.; Motkov, M.M.; Cherkasov, S.O. Influence of heat treatment on the structure and properties of an Al-7\%REM conductive aluminum alloy casted in an electromagnetic crystallizer. Phys. Met. Metallogr. 2020, 121, 173-179. [CrossRef]

8. Mogucheva, A.A.; Zyabkin, D.V.; Kaibyshev, R.O. Effect of annealing on the structure and properties of aluminum alloy Al-8\%MM. Met. Sci. Heat Treat. 2012, 53, 450-454. [CrossRef]

9. Murashkin, M.Y.; Sabirov, I.; Medvedev, A.E.; Enikeev, N.A.; Lefebvre, W.; Valiev, R.Z.; Sauvage, X. Mechanical and electrical properties of an ultrafine grained $\mathrm{Al}-8.5 \mathrm{wt} . \% \mathrm{RE}(\mathrm{RE}=5.4 \mathrm{wt} . \% \mathrm{Ce}, 3.1 \mathrm{wt} . \% \mathrm{La})$ alloy processed by severe plastic deformation . Mater. Des. 2016, 90, 433-442. [CrossRef]

10. Medvedev, A.E.; Murashkin, M.Y.; Enikeev, N.A.; Valiev, R.Z.; Hodgson, P.D.; Lapovok, R. Enhancement of mechanical and electrical properties of Al-Re alloys by optimizing rare-earth concentration and thermo-mechanical treatment. J. Alloy. Compd. 2018, 745, 696-704. [CrossRef]

11. Wang, W.; Pan, Q.; Lin, G.; Wang, X.; Sun, Y.; Wang, X.; Ye, J.; Sun, Y.; Yu, Y.; Jiang, F.; et al. Microstructure and properties of novel $\mathrm{Al}-\mathrm{Ce}-\mathrm{Sc}, \mathrm{Al}-\mathrm{Ce}-\mathrm{Y}, \mathrm{Al}-\mathrm{Ce}-\mathrm{Zr}$ and Al-Ce-Sc-Y alloy conductors processed by die casting, hot extrusion and cold drawing. J. Mater. Sci. Technol. 2020, 58, 155-170. [CrossRef]

12. Sidelnikov, S.B.; Voroshilov, D.S.; Motkov, M.M.; Timofeev, V.N.; Konstantinov, I.L.; Doyzhenko, N.N.; Lopatina, E.S.; Bespalov, V.M.; Sokolov, R.E.; Mansurov, Y.N.; et al. Investigation structure and properties of wire from the alloy of Al-REM system obtained with the application of casting in the electromagnetic mold, combined rolling-extrusion, and drawing. Int. J. Adv. Manuf. Technol. 2021, 114, 2633-2649. [CrossRef]

13. Mavlyutov, A.M.; Orlova, T.S.; Latynina, T.A.; Kasatkin, I.A.; Murashkin, M.Y.; Valiev, R.Z. Influence of additional deformation on microstructure, mechanical and electrical properties of Al-Mg-Si alloy processed by high pressure torsion. Rev. Adv. Mater. Sci. 2017, 52, 61-69.

14. Lokshin, M.Z.; Sirotinskij, M.S.; Zakharov, V.V.; Komarov, V.M. Method for Making Electrical Wire of Aluminium Alloys. Patent RU 2141389 C1. Application No. 98111393/02, 20 November 1989.

15. Pozdnyakov, A.V.; Barkov, R.Y. Effect of impurities on the phase composition and properties of new alloy of the Al-Y-Er-Zr-Sc system. Metallurgist 2019, 63, 79-86. [CrossRef]

16. Zakharov, V.V.; Ficenko, I.A. Some principles of alloying of aluminum alloys with scandium and zirconium in ingot production of deformed semiproducts. Met. Sci. Heat Treat. 2019, 61, 217-221. [CrossRef]

17. Barkov, R.Y.; Mikhaylovskaya, A.V.; Yakovtseva, O.A.; Loginova, I.S.; Prosviryakov, A.S.; Pozdniakov, A.V. Effect of thermomechanical treatment on the microstructure, precipitation strengthening, internal friction, and thermal stability of Al-Er-Yb-Sc alloys with good electrical conductivity. J. Alloy. Compd. 2021, 855, 157367. [CrossRef]

18. Pozdnyakov, A.V.; Barkov, R.Y.; Prosviryakov, A.S.; Churyumov, A.Y.; Golovin, I.S.; Zolotorevskiy, V.S. Effect of Zr on the microstructure, recrystallization behavior, mechanical properties and electrical conductivity of the novel Al-Er-Y alloy. J. Alloy. Compd. 2018, 765, 1-6. [CrossRef]

19. Barkov, R.Y.; Pozdnyakov, A.V. Heat-Resistant Electrically Conductive Aluminum Alloys (Options). Patent RU 2743499 C1. Application No. 2020125487, 19 February 2021.

20. Nokhrin, A.; Shadrina, I.; Chuvil'deev, V.; Kopylov, V. Study of structure and mechanical properties of fine-grained aluminum alloys Al-0.6wt.\%Mg-Zr-Sc with ratio Zr:Sc = 1.5 obtained by cold drawing. Materials 2019, 12, 316. [CrossRef] 
21. Chuvil'deev, V.N.; Gryaznov, M.Y.; Shotin, S.V.; Kopylov, V.I.; Nokhrin, A.V.; Likhnitskii, C.V.; Chegurov, M.K.; Bobrov, A.A.; Tabachkova, N.Y.; Pirozhnikova, O.E. Investigation of superplasticity and dynamic grain growth in ultrafine-grained $\mathrm{Al}-0.5 \% \mathrm{Mg}-$ Sc alloys. J. Alloy. Compd. 2021, 877, 160099. [CrossRef]

22. Barkov, R.Y.; Yakovtseva, O.A.; Mamzurina, O.I.; Loginova, I.S.; Medvedeva, S.V.; Prosviryakov, A.S.; Mikhaylovskaya, A.V.; Pozdniakov, A.V. Effect of $\mathrm{Yb}$ on the structure and properties of an electroconductive Al-Y-Sc alloy. Phys. Met. Metallogr. 2020 121, 604-609. [CrossRef]

23. Morozova, A.; Mogucheva, A.; Bukin, D.; Lukianova, O.; Korotkova, N.; Belov, N.; Kaibyshev, R. Effect of Si and Zr on the microstructure and properties of Al-Fe-Si-Zr alloys. Metals 2017, 7, 495. [CrossRef]

24. Zakharov, V.V.; Fisenko, I.A. Alloying aluminum alloys with scandium. Met. Sci. Heat Treat. 2017, 59, 278-284. [CrossRef]

25. Zakharov, V.V. Cobmined alloying of aluminum alloys with scandium and zirconium. Met. Sci. Heat Treat. 2014, 56, 281-286. [CrossRef]

26. Latynina, T.A.; Mavlyutov, A.M.; Valiev, R.Z.; Murashkin, M.Y.; Orlova, T.S. The effect of hardening by annealing in ultrafinegrained Al-0.4Zr alloy: Influence of Zr microadditives. Philos. Mag. 2019, 99, 2424-2443. [CrossRef]

27. Belov, N.; Korotkova, N.; Akopyan, T.; Murashkin, M.; Timofeev, V. Structure and properties of Al-0.6wt.\%Zr wire alloy manufactured by direct drawing of electromagnetically cast wire rod. Metals 2020, 10, 769. [CrossRef]

28. Belov, N.A.; Alabin, A.N.; Yakovlev, A.A. Influence of the annealing temperature on the phase composition of Al-0.55 wt $\% \mathrm{Zr}$ cast alloy. Russ. J. Non Ferr. Met. 2013, 54, 224-228. [CrossRef]

29. Belov, N.A.; Korotkova, N.O.; Akopyan, T.K.; Timofeev, V.N. Structure and properties of Al-0.6\%Zr-0.4\%Fe-0.4\%Si (wt.\%) wire alloy manufactured by electromagnetic casting. JOM 2020, 72, 1561-1570. [CrossRef]

30. Mikhaylovskaya, A.V.; Mochugovskiy, A.G.; Levchenko, V.S.; Tabachkova, N.Y.; Mufalo, W.; Portnoy, V.K. Precipitation behavior of $\mathrm{L1}_{2} \mathrm{Al}_{3} \mathrm{Zr}$ phase in Al-Mg-Zr alloy. Mater. Charact. 2018, 139, 30-37. [CrossRef]

31. Mavlyutov, A.M.; Bondarenko, A.S.; Muraskin, M.Y.; Boltynjuk, E.V.; Vailev, R.Z.; Orlova, T.S. Effect of annealing on microhardness and electrical resistivity of nanostructured SPD aluminum. J. Alloy. Compd. 2017, 698, 539-546. [CrossRef]

32. Pozdnyakov, A.V.; Osipenkova, A.A.; Popov, D.A.; Makhov, S.V.; Napalkov, V.I. Effect of low additions of Y, Sm, Gd, Hf and Er on the structure and hardness of alloy Al-0.2\%Zr-0.1\%Sc. Met. Sci. Heat Treat. 2017, 58, 537-542. [CrossRef]

33. Wen, S.P.; Gao, K.Y.; Huang, H.; Wang, W.; Nie, Z.R. Role of Yb and Si on the precipitation hardening and recrystallization of dilute Al-Zr alloy. J. Alloy. Compd. 2014, 599, 65-70. [CrossRef]

34. Wen, S.P.; Gao, K.Y.; Li, Y.; Huang, H.; Nie, Z.R. Synergetic effect of Er and Zr on the precipitation hardening of Al-Er-Zr alloy. Scr. Mater. 2011, 65, 592-595. [CrossRef]

35. GOST 10446-80 (ISO 6892-84). Tensile Test Method; USSR State Committee on Standards: Moscow, Russia, 1982.

36. Hug, E.; Bellido, N. Brittleness study of intermetallic $(\mathrm{Cu}, \mathrm{Al})$ layers in copper-clad aluminum thin wires. Mater. Sci. Eng. A 2011, 528, 7103-7106. [CrossRef]

37. Gueydan, A.; Domenges, B.; Hug, E. Study of the intermetallic in copper-clad aluminum wires after thermal aging. Intermetallics 2014, 50, 34-42. [CrossRef]

38. Lee, W.-B.; Bang, K.-S.; Jung, S.-B. Effects of intermetallic compound on the electrical and mechanical properties of friction welded $\mathrm{Cu} / \mathrm{Al}$ bumetallic joints during annealing. J. Alloy. Compd. 2005, 390, 212-219. [CrossRef]

39. Shamtko, O.A.; Usov, Y.V. Structure and Properties of Metals and Alloys. Electrical and Magnetic Properties of Metals; Naukova Dumka: Kiev, Ukraine, 1987; p. 325. (In Russian)

40. Chuvil'deev, V.N.; Nokhrin, A.V.; Smirnova, E.S.; Kopylov, V.I. Solid solution decomposition mechanisms in cast and microcrystalline Al-Sc alloys: III. Analysis of experimental data. Russ. Metall. 2012, 11, 985-993. [CrossRef]

41. Chuvil'deev, V.N.; Smirnova, E.S.; Kopylov, V.I. Solid solution decomposition mechanisms in cast and microcrystalline Al-Sc alloys: II. Model for the decomposition of a solid solution during the formation of coherent second-phase particles. Russ. Metall. 2012, 7, 612-624. [CrossRef]

42. Rokhlin, L.L.; Bochvar, N.R.; Boselli, J.; Dobatkina, T.V. Investigation of phase relations in the Al-rich alloys of the Al-Sc-Hf system in solid state. J. Phase Equilibria Diffus. 2010, 31, 327-332. [CrossRef]

43. Popova, E.; Kotenkov, P.; Shubin, A.; Gilev, I. Formation of metastable aluminides in Al-Sc-Ti(Zr,Hf) cast alloys. Met. Mater. Int. 2020, 26, 1515-1523. [CrossRef]

44. Chuvil'deev, V.N.; Nokhrin, A.V.; Smirnova, E.S.; Kopylov, V.I. Solid solution decomposition mechanisms in as-cast and microcrystalline Al-Sc alloys: IV. Effect of the decomposition of a solid solution on the mechanical properties of the alloys. Russ. Metall. 2013, 9, 676-690. [CrossRef]

45. Martin, J.W. Micromechanisms in Particle-Hardened Alloys; Cambridge University Press: Cambridge, UK, 1980 ; p. 167.

46. Larikov, L.N.; Isaychev, V.I. Diffusion in Metals and Alloys. Handbook; Naukova Dumka: Kiev, Ukraine, 1987; p. 509. (In Russian)

47. Chuvil'deev, V.N. Nonequilibrium Grain Boundary in Metals. Theory and Applications; Fizmatlit: Moscow, Russia, $2004 ;$ p. 304. (In Russian)

48. Chuvil'deev, V.N.; Smirnova, E.S. Effect of small impurity concentrations on the diffusive properties of grain boundaries. Phys. Met. Metallogr. 1999, 88, 67-72.

49. Chuvil'deev, V.N.; Smirnova, E.S. Recrystallization temperature in metals with small impurity additions. Phys. Met. Metallogr. 2001, 92, 117-122. 